NANO: Brief Reports and Reviews

Vol. 14, No. 9 (2019) 1950108 (16 pages)

(C) World Scientific Publishing Company

DOI: $10.1142 / S 179329201950108 X$

\title{
Facile Fabrication of Nitrogen, Phosphorus and Silicon Co-Doped Porous Carbon as an Efficient Oxygen Reduction Catalyst for Primary Zn-Air Battery
}

\author{
Renxing Huang*, \\ Xingyong Liu ${ }^{*, \dagger}$ and Honghui Wang, ${ }^{*}, \boldsymbol{\Phi}, \|$ \\ *College of Chemical Engineering \\ Sichuan University of Science $\&$ Engineering \\ Zigong 643000, P. R. China \\ ${ }^{\dagger}$ Collaborative Innovation Center of Industrial \\ Organic Solid Waste Resource Disposal \\ Sichuan University of Science $\&$ Engineering \\ Zigong 643000, P. R. China \\ ¥Material Corrosion and Protection Key \\ Laboratory of Sichuan Province \\ Sichuan University of Science $\mathcal{G}$ Engineering \\ Zigong 643000, P. R. China \\ \$lynnely1209@sina.com \\ 『whh@cdut.edu.cn
}

Received 12 June 2019

Accepted 19 July 2019

Published 19 September 2019

\begin{abstract}
It is highly pleasurable but challenging to develop economical and efficient catalysts for accelerating the oxygen reduction reaction (ORR) endowed with sluggish kinetics involved in renewable energy conversion and storage systems such as Zn-air batteries. Herein, N, P and Si tri-doped porous carbon (SiN-PA900) catalysts was prepared by a simple one-step pyrolysis strategy using the mixture of the ionic liquid formed by phytic acid (PA) and N-methylimidazole and tetraethyl orthosilicate (TEOS) as N, P, Si and carbon sources, and the PA as pore-foaming agent. The resulting SiN-PA900 shows favorable catalytic activity toward ORR with an onset potential of $0.94 \mathrm{~V}$ versus RHE, half-wave potential of $0.81 \mathrm{~V}$ versus RHE, robust stability and excellent tolerance for methanol in alkaline medium, which are comparable to those of the commercial $20 \% \mathrm{Pt} / \mathrm{C}$. More impressively, the assembled primary Zn-air battery employing the SiN-PA900 as cathode catalysts can achieve a peak power density of $181.4 \mathrm{~mW} / \mathrm{cm}^{2}$. Those encouraging properties could be attributed to a synergistic effect of the doped N, P and Si atoms in the carbon matrix, good surface wettability, high surface areas and hierarchical porous structures for sufficient contact and rapid transportation of the reactants in terms of composition and structures.
\end{abstract}

Keywords: Oxygen reduction reaction; ORR catalysts; co-doped; porous carbon; Zn-air batteries.

${ }$ Corresponding authors. 


\section{Introduction}

The development of energy conversion and energy storage technology provides an effective approach for alleviating the energy crisis and for sustainable development of resources. ${ }^{1-3}$ Metal-air batteries and fuel cells have arisen as promising energy conversion and storage devices with wide application potential in the fields of transportation, stationary and portable power generation owing to their high energy efficiency, environmental friendliness and zero carbon emission. ${ }^{4,5}$ Among them, the Zn-air battery has been regarded as one of the most promising energy storage devices due to its high theoretical energy density (1086 Wh/kg), abundant resource and low cost. ${ }^{6,7}$ However, catalysts are usually required to overcome the sluggish kinetics of the oxygen reduction reaction (ORR) regarded as one of the most critical reactions during the operation of zinc-air batteries. ${ }^{8-10}$ Currently, precious $\mathrm{Pt}$ or Pt-based catalysts are considered to be the state-ofthe-art electrocatalysts for the ORR, whereas the scarcity of resources, prohibitive cost and unsatisfactory stability badly restrict their wide applications. ${ }^{11,12}$ Therefore, it is imperative to develop highly efficient, low-cost and durable cathode catalysts applied to the Zn-air battery. ${ }^{13}$

Accordingly, nonprecious metal catalysts have been studied extensively to reduce or replace precious metal catalysts for the energy conversion and energy storage technologies. ${ }^{8}$ Among various alternatives, carbon materials doped with heteroatoms $(\mathrm{B}, \mathrm{N}, \mathrm{P}, \mathrm{S}, \mathrm{Cl}, \mathrm{Br}$ and I) have become the most promising option due to their prominent electrocatalytic activity, excellent endurance performance and relatively low cost. ${ }^{14}$ As for heteroatom-doped carbon materials, the improved catalytic performance could be attributed to heteroatoms inducing charge delocalization of adjacent carbon atoms related to $\mathrm{O}_{2}$ absorption mode within the carbon structure during the ORR process. ${ }^{15}$ For example, previous experimental researches and the DFT calculations have proved that nitrogen-doped carbon could be the most promising electrocatalyst towards ORR due to its high electronegativity and difference in bond length and atomic size favorable for charge delocalization of adjacent carbon atoms. ${ }^{16-18} \mathrm{In}$ order to further increase its catalytic activity, unitary $\mathrm{N}$-doped carbon material can be modified via the additional doping of other heteroatoms owing to the difference in electronegativity of heteroatoms causing transformation of charge densities of adjacent carbon atoms. ${ }^{19,20}$ Furthermore, the ORR electrocatalytic activity of carbon materials is also affected by their size, structure and shape, etc. ${ }^{21,22}$ Ramasahayam et al. successfully prepared N, P and Si tri-doped carbon catalyst for ORR by microwave assisted method. ${ }^{18}$ Despite the use of novel method in the development of advanced ORR catalysts, the present electrocatalytic properties are still far from desirable results, presumably owing to nonoptimal doping amount of N, P and Si, big flake-like structures (diameter $>100 \mathrm{~nm}$ ), small specific surface area and dominant micropores. ${ }^{18,23}$ Recently, some research indicates that ionic liquid (IL) is a kind of promising nitrogen/carbon source for the synthesis of nitrogen-doped carbons. ${ }^{24-26}$ ILs can be used to tailor the amount of heteroatom-doping and uniformity of distribution of heteroatoms in the resulting carbon materials due to their good compatibility with a variety of compounds and their architectures allowing for a wide combination of anions and cations. ${ }^{27,28}$ Here, we designed a simple and straightforward approach, pyrolyzing the mixture of TEOS and the IL consisting of N-methylimidazole and phytic acid (PA) solution in one step, to synthesize N, P and Si co-doped 3D porous carbon materials. The obtained SiN-PA900 exhibited outstanding ORR activity, long-term stability and better tolerance for methanol, which were comparable to that of the commercial $20 \% \mathrm{Pt} / \mathrm{C}$. The satisfactory ORR performance could benefit from the reasonable content of $\mathrm{Si}$ (3.59 at\%), N (4.08 at\%) and $\mathrm{P}$ (3.41 at\%), 3D fluffy structures and a high specific surface area $\left(684.7 \mathrm{~m}^{2} / \mathrm{g}\right)$ due to uniform distribution of heteroatoms $(\mathrm{N}, \mathrm{P}$ and $\mathrm{Si}$ ) in the precursor and self-pore-creating property of the PA.

\section{Experimental Section}

\subsection{Sample preparation}

The N, P and Si co-doped porous carbon was prepared by pyrolyzing the precursors composed of PA, N-methylimidazole and tetraethyl orthosilicate (TEOS). Typically, $2 \mathrm{~mL} \mathrm{~N}$-methylimidazole and $2 \mathrm{~mL}$ TEOS were added into $2.6 \mathrm{~mL}$ PA solution $(50 \%, \mathrm{wt} / \mathrm{wt}$ in water $)$, and stirred at room temperature for $12 \mathrm{~h}$ to remove part of water. The partially dried product was thermally treated under $\mathrm{N}_{2}$ atmosphere at $350^{\circ} \mathrm{C}$ for $1 \mathrm{~h}$ with a heating rate of $5^{\circ} \mathrm{C} / \mathrm{min}$. Then the temperature was raised to 
$900^{\circ} \mathrm{C}$ with a rate of $5^{\circ} \mathrm{C} / \mathrm{min}$ and held for another $2 \mathrm{~h}$. The obtained product was named SiN-PA900. For comparison, other catalysts were prepared without the presence of $\mathrm{N}$-methylimidazole or TEOS using the similar procedure described above. The obtained samples were named as N-PA900 (without TEOS), PA900 (without N-methylimidazole and TEOS) and Si-PA900 (without N-methylimidazole). Similarly, the samples obtained at the temperature $800^{\circ} \mathrm{C}$ and $1000^{\circ} \mathrm{C}$ were labeled as SiNPA800 and SiN-PA1000 in turn. The obtained porous carbon can be directly used as catalysts without further treatment.

\subsection{Physical characterizations}

The morphology and structures of the obtained products were characterized by scanning electron microscopy (SEM, JSM-7500F, JEOL Ltd., Japan) and high-resolution transmission electron microscopy (HRTEM, Tecnai-G20, FEI Company, USA) operated at $200.0 \mathrm{kV}$. The crystal structure and composition of the prepared catalysts were investigated via Bruker D2 PHASER X-ray diffractometer $(\lambda \mathrm{Cu}-\mathrm{K} \alpha=0.15148 \mathrm{~nm}, 30 \mathrm{kV}, 20.0 \mathrm{~mA})$. Raman spectra were performed with a DXR Raman spectrometer (Thermo Fisher Co., USA) at an excitation wavelength of $532 \mathrm{~nm}$. Nitrogen adsorptiondesorption measurements were investigated at $77.4 \mathrm{~K}$ on the TriStar II Plus 2.02 system (Micromeritics Instrument Corp., USA). Specific surface area (SBET) was determined by BrunauerEmmett-Teller (BET, 3H-2000PM2, BeiShiDe Instrument Technology (Co., Ltd.)) method. XPS analysis was performed using an ESCALAB 250 XI $\mathrm{X}$-ray photoelectron spectrometer (Thermo Fisher Co., USA).

\subsection{Electrochemical measurements}

The ORR activities of the catalysts were studied at room temperature in a standard three-electrode electrochemical cell on AUTOLAB electrochemical system which was connected to Pine rotating ringdisk electrode (RRDE) in $0.10 \mathrm{M} \mathrm{KOH}$ solution. The studied material coated RDE or RRDE, Ag/ $\mathrm{AgCl}$ with saturated $\mathrm{KCl}$ and a platinum wire, which were used as working electrode, reference electrode and counter electrode, respectively. All the potentials were calibrated versus the reversible hydrogen electrode (RHE), $E(\mathrm{RHE})=E(\mathrm{Ag} /$ $\mathrm{AgCl})+0.97 .{ }^{29}$ Prior to use, the rotating disk electrode (RDE with $5 \mathrm{~mm}$ diameter and $0.19625 \mathrm{~cm}^{2}$ surface area) or the rotating ring-disk electrode (RRDE comprising of a glassy carbon disk with diameter of $5.61 \mathrm{~mm}$ and surface area of $0.2475 \mathrm{~cm}^{2}$, and a Pt ring with area of $0.1866 \mathrm{~cm}^{2}$ ) was hand-polished using $0.05 \mu \mathrm{m}$ alumina slurry on chamois leather, washed with distilled water and then dried in air. Two miligrams catalyst and $10 \mu \mathrm{L}$ of Nafion solution ( $5 \mathrm{wt} . \%$ ) were dispersed in $500 \mu \mathrm{L}$ of $3: 1(\mathrm{v} / \mathrm{v})$ water/isopropanol then treated by ultrasonication for $2 \mathrm{~h}$ to form a homogeneous catalyst ink. The working electrode was prepared by casting $7 \mu \mathrm{L}$ catalyst ink onto glassy carbon electrode. The loading mass of the catalysts was $142.16 \mu \mathrm{g} / \mathrm{cm}^{2}$.

Cyclic voltammetry (CV) profiles were recorded in $\mathrm{O}_{2}$-saturated $0.10 \mathrm{M} \mathrm{KOH}$ or $\mathrm{N}_{2}$-saturated solution with a scan rate of $50 \mathrm{mV} / \mathrm{s}$ from $0.172 \mathrm{~V}$ to $1.072 \mathrm{~V}$ versus RHE. The linear sweep voltammetry (LSV) curves were performed in $\mathrm{O}_{2}$-saturated $0.10 \mathrm{M} \mathrm{KOH}$ with a scan rate of $10 \mathrm{mV} / \mathrm{s}$ from $1.02 \mathrm{~V}$ to $0.172 \mathrm{~V}$ versus RHE at different rotation rates (400-2025 rpm). The electron number per oxygen molecule during ORR on the basis of RDE data can be calculated from the Koutechy-Levich equation as follows ${ }^{30}$ :

$$
\frac{1}{j}=\frac{1}{j_{k}}+\frac{1}{j_{d}}=\frac{1}{j_{k}}+\frac{1}{B \omega^{1 / 2}}
$$

where $j, j_{k}$ and $j_{d}$ are the measured current density, the kinetic current densities and diffusion limiting current densities, respectively, $\omega$ is the electrode rotation speed, $B$ is determined from the slope of the Koutechy-Levich (K-L) plots according to the Levich equation as follows:

$$
B=0.2 n F\left(D_{\mathrm{O}_{2}}\right)^{2 / 3} v^{-1 / 6} C_{\mathrm{O}_{2}},
$$

where $n$ represents the transferred electron number per oxygen molecule, $F$ is Faraday constant $(96485 \mathrm{C} / \mathrm{mol}), D_{\mathrm{O}_{2}}$ is the diffusion coefficient of $\mathrm{O}_{2}$ in $0.10 \mathrm{M} \mathrm{KOH}\left(D_{\mathrm{O}_{2}}=1.86 \times 10^{-5} \mathrm{~cm}^{2} / \mathrm{s}\right), v$ is the kinetic viscosity of the solution $\left(v=0.01 \mathrm{~cm}^{2} / \mathrm{s}\right)$, $C_{\mathrm{O}_{2}}$ is the bulk concentration of $\mathrm{O}_{2}$ in electrolyte $\left(1.21 \times 10^{-6} \mathrm{~mol} / \mathrm{cm}^{3}\right)$. The constant 0.2 is adopted when rotation speed is expressed in rpm. ${ }^{31}$

For the RRDE measurements, the loading mass of the catalysts was $142.16 \mu \mathrm{g} / \mathrm{cm}^{2}$. The disk electrode was scanned at a rate of $10 \mathrm{mV} / \mathrm{s}$, and the ring 
potential was constant at $1.5 \mathrm{~V}$ versus RHE. The $\% \mathrm{HO}_{2}^{-}$and the electron number transferred $(n)$ were determined by the following equations ${ }^{29}$ :

$$
\begin{gathered}
\% \mathrm{HO}_{2}^{-}=100 \frac{2 I_{R} / N}{I_{D}+\left(I_{R} / N\right)}, \\
n=4 \frac{I_{D}}{I_{D}+\left(I_{R} / N\right)},
\end{gathered}
$$

where $I_{D}, I_{R}$ and $N=0.37$ are the Faradaic current at the disk, Faradaic current at the ring and collection efficiency of the ring electrode, respectively.

The ORR stability test in $\mathrm{O}_{2}$-saturated $0.10 \mathrm{M}$ $\mathrm{KOH}$ electrolyte was conducted by recording the current change of the working electrode at halfwave potential for $10000 \mathrm{~s}$ at $1600 \mathrm{rpm}$.

The primary zinc-air battery test was performed at $25^{\circ} \mathrm{C}$ with a scan rate of $10 \mathrm{mV} / \mathrm{s}$. The self-assembled zinc-air batteries were made of a positive air electrode, a membrane separator and a negative zinc electrode in $6.0 \mathrm{M} \mathrm{KOH}$ electrolyte. ${ }^{6}$ Particularly, the air electrode was composed of carbon sheets loaded with $1 \mathrm{mg} / \mathrm{cm}^{2}$ of SiN-PA900 or $20 \%$ $\mathrm{Pt} / \mathrm{C}$ catalysts, a nickel foam and waterproof membrane. Discharge polarization curves were measured by LSV at a scan rate of $10 \mathrm{mV} / \mathrm{s}$. Galvanostatic discharge curves of zinc-air batteries were performed at the current density of $10 \mathrm{~mA} / \mathrm{cm}^{2}$ for $24 \mathrm{~h}$.

\section{Result and Discussion}

\subsection{Material characterization}

The preparation process of the SiN-PA900 porous carbon is vividly illustrated in Scheme 1. First, PA interacts with N-methylimidazole to form an IL, and then co-pyrolysis of the mixture of IL and TEOS produces $\mathrm{Si}, \mathrm{N}$ and $\mathrm{P}$ co-doped $3 \mathrm{D}$ porous carbon materials. The morphology and structure of SiN-PA900 were characterized by SEM and HRTEM. Figures 1(a) and 1(b) show its 3D fluffy structures and graphitic crystallites. The SEM elemental mapping images [Fig. 1(c)] show that N, P and $\mathrm{Si}$ are distributed uniformly over the entire carbon matrix of the SiN-PA900. The X-ray diffraction (XRD) patterns of all the samples are displayed in Fig. 2(a). Two peaks are observed at approximately $24^{\circ}$ and $44^{\circ}$, which correspond to the $\left(\begin{array}{lll}0 & 0 & 2\end{array}\right)$ and $\left(\begin{array}{lll}1 & 0 & 0\end{array}\right)$ crystalline planes, respectively

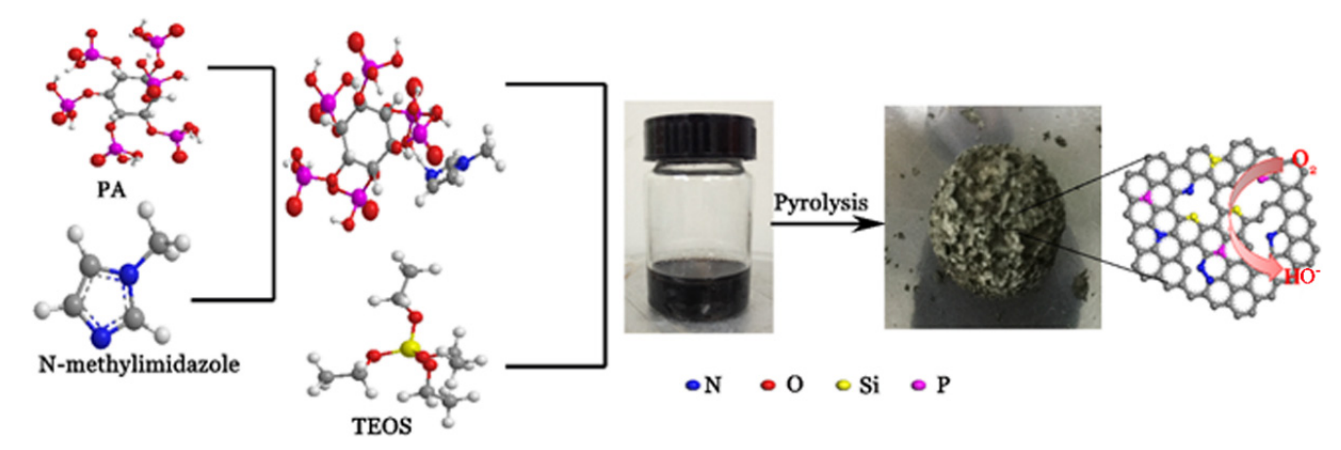

Scheme 1. Preparation process of SiN-PA900 porous carbon via interconnection and pyrolysis.
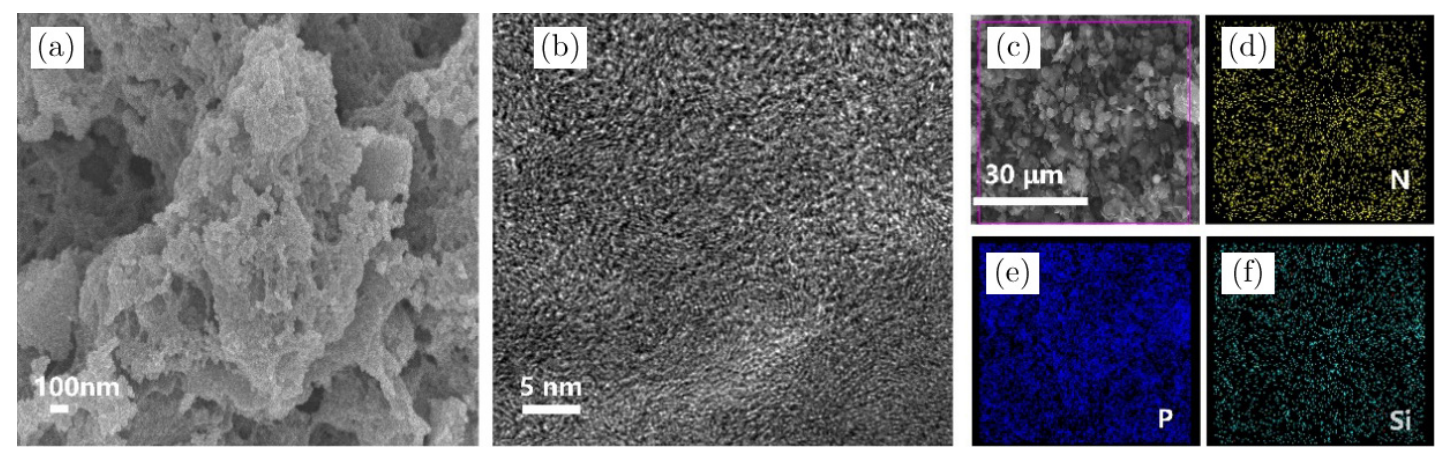

Fig. 1. Representative SEM (a) and HRTEM images (b) of SiN-PA900, (c-f) SEM image and corresponding elemental mappings of N, P and Si atoms for SiN-PA900 (nitrogen, phosphorus and silicon). 


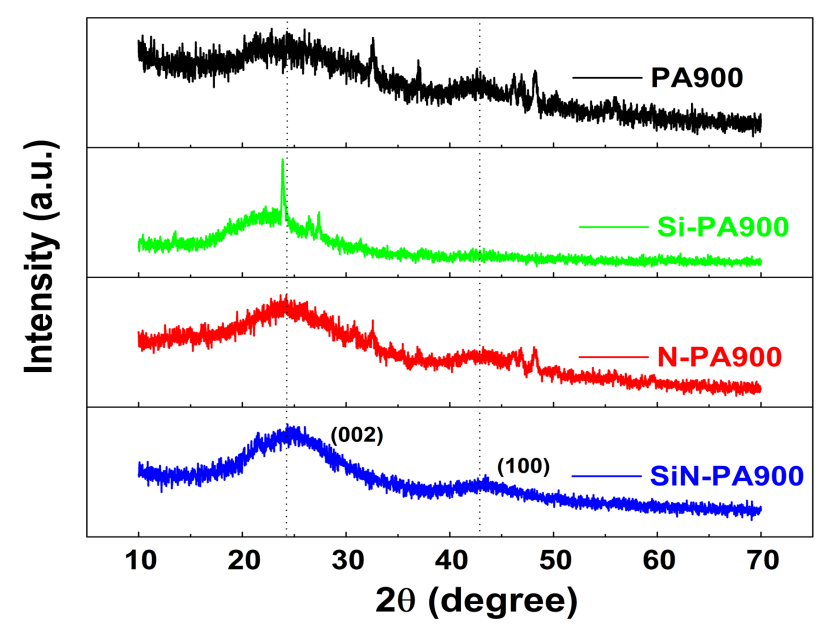

(a)

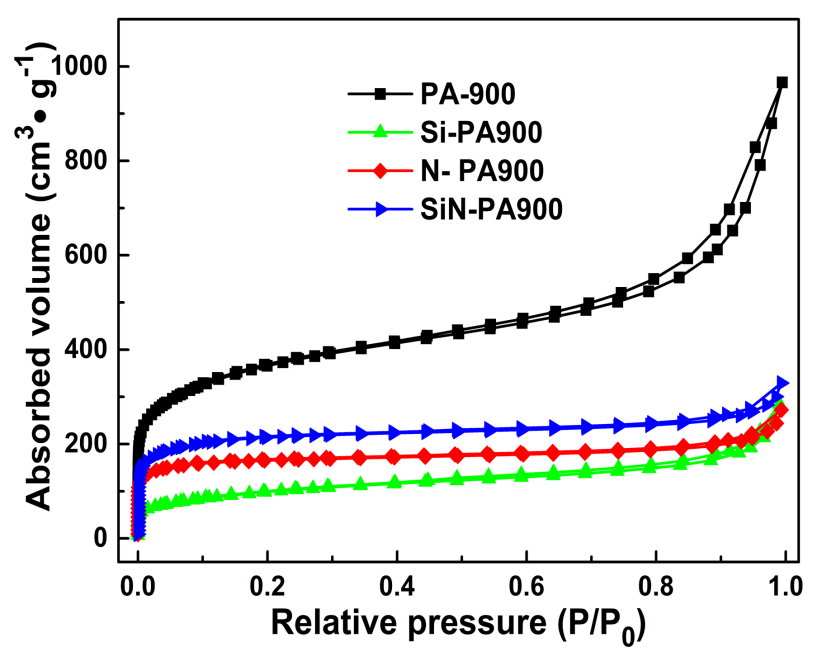

(c)

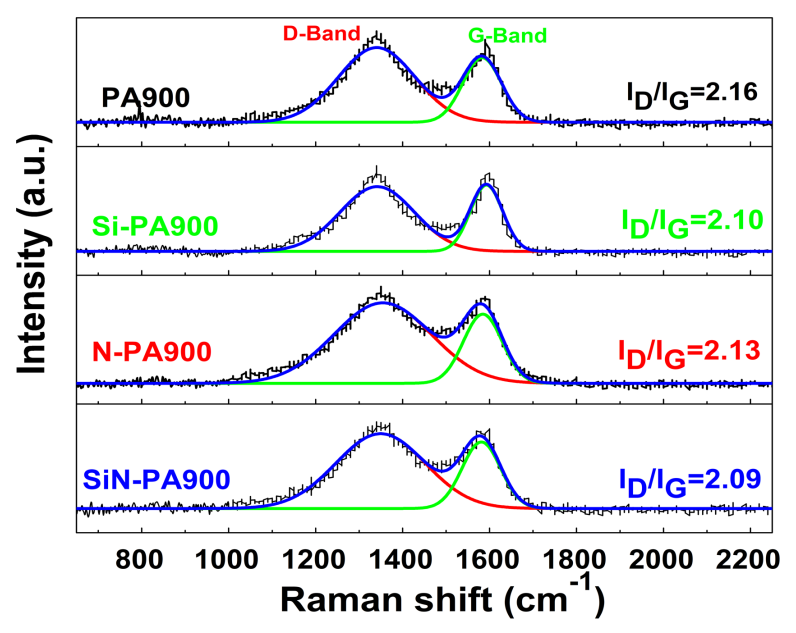

(b)

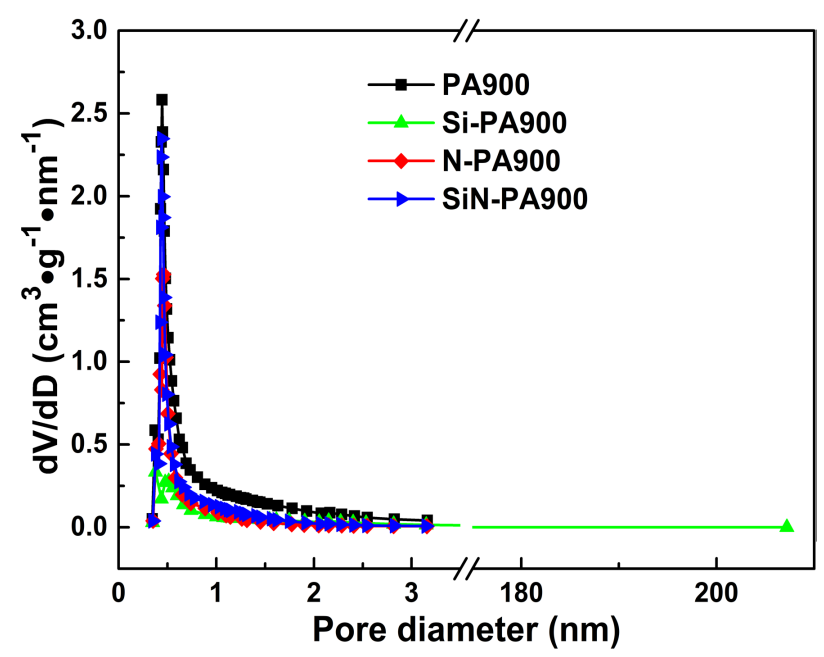

(d)

Fig. 2. (a) XRD patterns, (b) Raman spectra, (c) nitrogen adsorption-desorption isotherms and (d) corresponding pore-size distribution of PA900, Si-PA900, N-PA900 and SiN-PA900.

(JCPDS 26-0441 and 41-1487),,$^{32,33}$ indicating that the obtained samples are a partially crystallized structure. ${ }^{34}$ It is worth noting that Si-PA900 shows typical peaks of $\mathrm{H}_{8} \mathrm{Si}_{8} \mathrm{O}_{20}$ (JCPDS card no. 350060), indicating that TEOS is more easily hydrolyzed in acidic condition, but it was not hydrolyzed in a neutral solution of PA and N-methylimidazole. To further understand the structural information of the obtained samples, Raman analysis was carried out. As shown in Fig. 2(b), all the samples show two distinct $\mathrm{D}$ and $\mathrm{G}$ bands near $1340 \mathrm{~cm}^{-1}$ and $1590 \mathrm{~cm}^{-1}$, respectively, which confirms the presence of disordered carbon structural and graphitic phases. The peak intensity radio $\left(I_{D} / I_{G}\right)$ is widely used to investigate the level of defects in carbon materials. ${ }^{35,36}$ As can be seen, the $I_{D} / I_{G}$ value of all the samples decreases in the order of PA900 (2.16) $>$ N-PA900 (2.13) > Si-PA900 (2.10) > SiN-PA900 (2.09) [Fig. 2(b)], implying that the defects decrease in carbon networks successively and the degree of graphitization increases with the addition of $\mathrm{N}$-methylimidazole and TEOS. ${ }^{16}$

$\mathrm{N}_{2}$ adsorption-desorption isotherm experiments were performed to further investigate the textural properties of PA900, Si-PA900, N-PA900 and SiNPA900. As shown in Fig. 2(c), all the samples have similar-type IV isotherm with hysteresis loop, indicating the existence of microporous and mesoporous structures. The Brunauer-Emmett-Teller (BET) surface areas of PA900, Si-PA900, N-PA900 and SiNPA900 are determined to be $1233.8 \mathrm{~m}^{2} / \mathrm{g}, 343.8 \mathrm{~m}^{2} / \mathrm{g}$, $517.9 \mathrm{~m}^{2} / \mathrm{g}$ and $684.7 \mathrm{~m}^{2} / \mathrm{g}$, respectively. PA900 
achieves a so high surface area without use of any template, which can be attributed to the poregenerating ability of six phosphorus-containing functional groups in the PA. ${ }^{37}$ However, the specific surface area of the other samples is significantly lower than that of PA900, probably due to pore blockage caused by the pyrolysis products of $\mathrm{N}$-methylimidazole and TEOS. Furthermore, the pore size distribution based on the density functional theory model is shown in Fig. 2(d) and Table S1, and the corresponding pore size distribution of the four samples mainly concentrates in the micropore range of $0.3-1.0 \mathrm{~nm}$. By contrast, the micropore volume of SiN-PA900, N-PA900 and Si-PA900 is less than that of PA900. The results show a similar trend as that of the specific surface area, which may also be caused by similar reasons that the pyrolysates of the N-methylimidazole and TEOS block the pore structure. Contact angle test results (Fig. S1) demonstrate that the as-obtained samples are hydrophilic, which can facilitate the transfer of electrolyte to the electrode surface. $^{38}$ As ORR mainly occurs at a triple boundary consisting of catalyst, electrolyte and $\mathrm{O}_{2}$, the high BET surface area, proper pore size distribution and well-hydrophilic property could favor for mass transportation of reactants and electrolytes. ${ }^{39,40}$

Furthermore, X-ray photoelectron spectroscopy (XPS) was performed to determine the surface element composition and chemical states. As can be seen in Fig. 3(a) and Table S2, the full XPS spectrum of SiN-PA900 shows five predominant peaks at $103.1,133.4,284.2,400.08$ and $532.6 \mathrm{eV}$, corresponding to Si2p, P2p, C1s, N1s and O1s signals, respectively, and their relative contents are $3.59 \%$, $3.41 \%, 74.37 \%, 4.08 \%$ and $14.55 \%$. The P2p spectra [Fig. 3(b) and Fig. S2(b)] of SiN-PA900 can be deconvoluted into two different bands at $132.9 \mathrm{eV}$ and $134.1 \mathrm{eV}$, corresponding to $\mathrm{P}-\mathrm{C}$ and $\mathrm{P}-\mathrm{O}$ banding. Supposedly, it is advantageous for the ORR that $\mathrm{P}$-doping can induce negative delocalization of $\mathrm{C}$ atoms adjacent to $\mathrm{P}$ atoms as a result of the lower electronegativity of $\mathrm{P}$ (2.19) than that of $\mathrm{C}$ atom (2.55). ${ }^{32,34}$ The N1s spectrum of SiNPA900 in Fig. 3(c) shows four types of $\mathrm{N}$ species, corresponding to pyridinic-N $(398.7 \mathrm{eV})$, pyrrolic-N $(400.3 \mathrm{eV})$, quaternary-N (401.4 eV) and oxidized-N $(402.1 \mathrm{eV}) ., 34,39$ As reported, three kinds of $\mathrm{N}$ structure (pyridinic-N, pyrrolic-N and quaternary-N) can promote ORR performance. ${ }^{41}$ The highresolution Si2p spectrum for SiN-PA900 is shown in Fig. 3(d), and it shows three types of $\mathrm{Si}$ species, corresponding to Si-C (101.6 eV), C-Si-O (102.4 eV) and $\mathrm{SiO}_{2}(103.6 \mathrm{eV}) .^{42}$ According to previous reports, Si-doping changes the charge density and energetic characteristics of carbon framework, which is advantageous for the ORR. ${ }^{42}$ Given that, during the ORR process, $\mathrm{O}_{2}$ absorption mode are usually affected by charge delocalization of adjacent

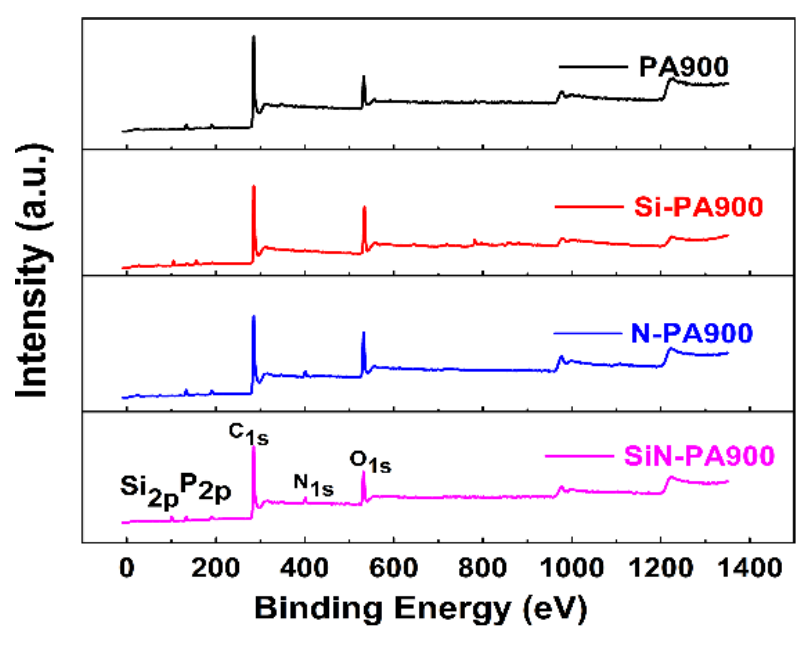

(a)

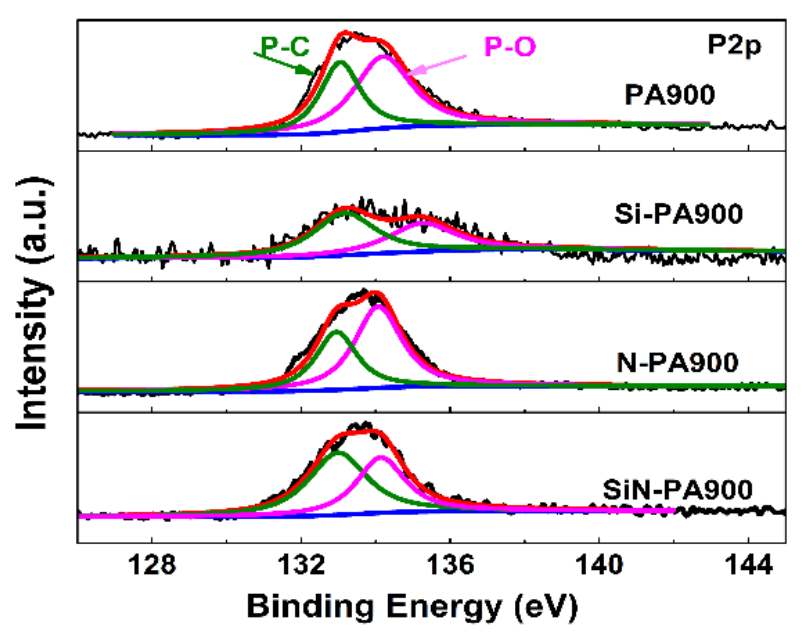

(b)

Fig. 3. (a) XPS survey spectra of PA900, Si-PA900, N-PA900 and SiN-PA900, the high-resolution XPS spectra of (b) P2p for the obtained samples, (c) the high-resolution XPS spectra of N1s and relative ratios of the four types of nitrogen for N-PA900 and SiN-PA900 and (d) the high-resolution XPS spectra of Si2p and the relative content of the $\mathrm{SiO}_{2}, \mathrm{C}-\mathrm{Si}-\mathrm{O}$ and C-Si for Si-PA900 and SiN-PA900. 


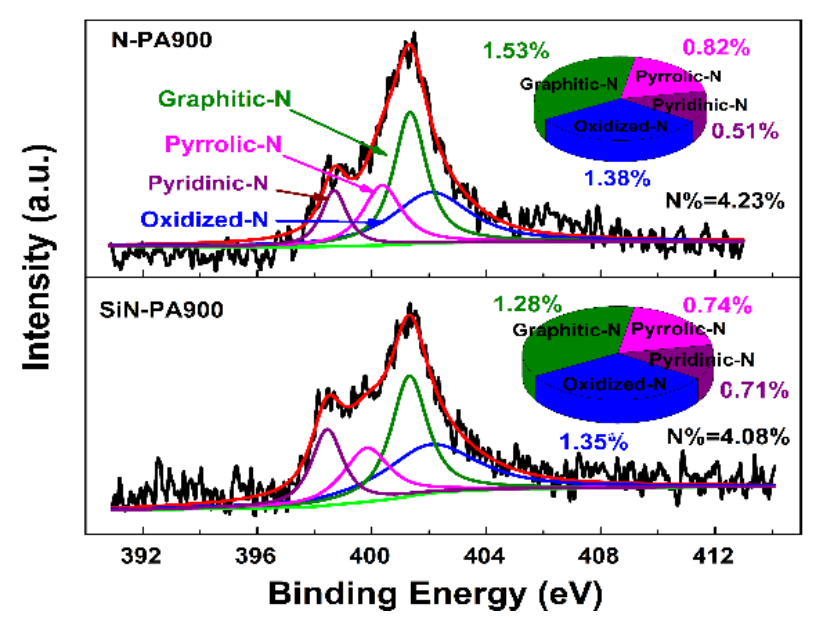

(c)

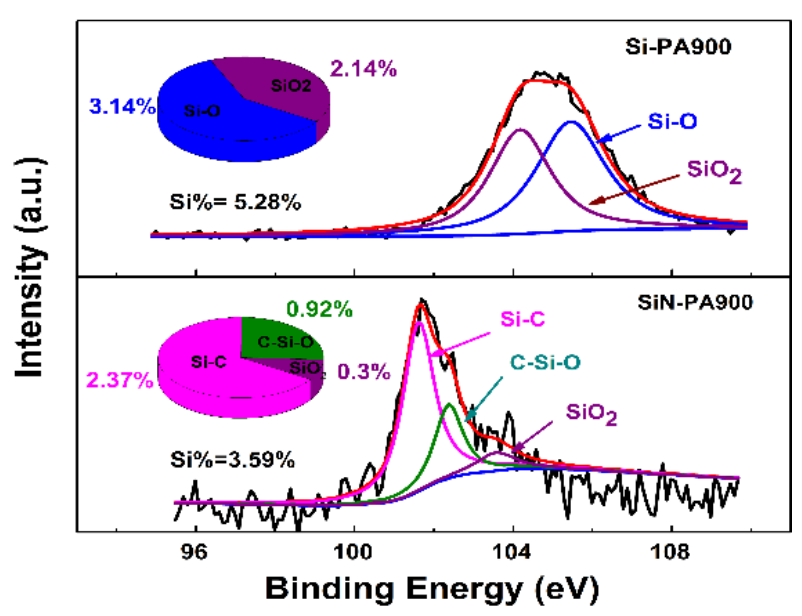

(d)

Fig. 3. (Continued)

carbon atoms within the carbon structure, codoping of N, P and Si inducing unique electronic structure could contribute to ORR activity.

\subsection{Evaluation of catalytic activity}

The catalytic ORR activity of all the samples and $20 \% \mathrm{Pt} / \mathrm{C}$ were measured on a rotating disk electrode. Both of CV and LSV were employed to evaluate the ORR activity of all samples. First the effect of pyrolysis temperature on the ORR activity of the samples was investigated and the results demonstrated that $900^{\circ} \mathrm{C}$ is the best pyrolysis temperature (Figs. S3 and S5). Furthermore, the other samples doped with different heteroatoms were also investigated by $\mathrm{CV}$ and the corresponding results are shown in Fig. S4. All the samples show redox peaks in $\mathrm{O}_{2}$-saturated $0.10 \mathrm{M} \mathrm{KOH}$ solution, but not in $\mathrm{N}_{2}$-saturated $0.10 \mathrm{M} \mathrm{KOH}$ solution. However, SiN-PA900 exhibits more positive ORR peak potential than other samples (SiN-PA900: 0.79 V, PA900: 0.73 V, Si-PA900: 0.74 V, N-PA900: $0.76 \mathrm{~V}$ ) indicating a better ORR activity. Meanwhile, LSV was recorded by a rotating disk electrode at a rotation speed of $1600 \mathrm{rpm}$ at a scan rate of $10 \mathrm{mV} / \mathrm{s}$. As presented in Figs. 4(a) and 4(c),

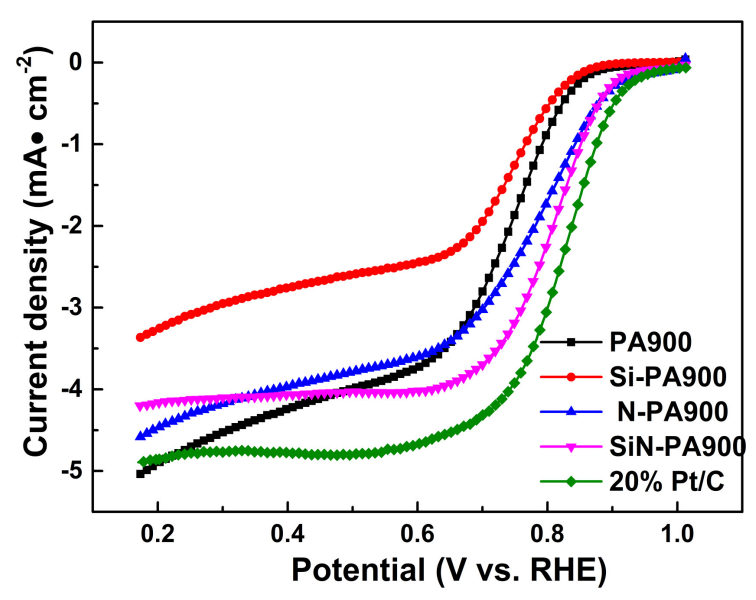

(a)

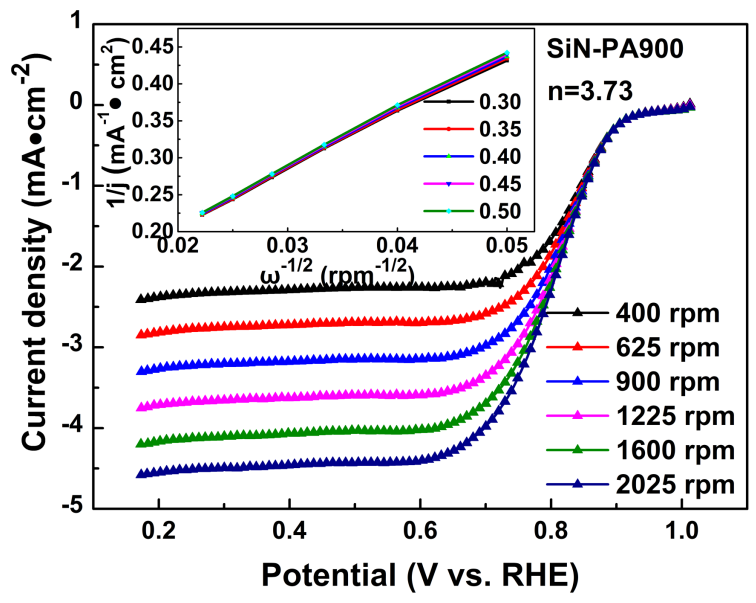

(b)

Fig. 4. (a) LSV curves for PA900, N-PA900, Si-PA900, SiN-PA900 and the commercial $20 \%$ Pt/C catalysts in an $\mathrm{O}_{2}$-saturated $0.10 \mathrm{M} \mathrm{KOH}$ at a rotation speed of $1600 \mathrm{rpm}$ at a scan rate of $10 \mathrm{mV} / \mathrm{s}$, (b) LSV curves of the SiN-PA900 samples with a scan rate of $10 \mathrm{mV} / \mathrm{s}$ at different rotating speeds and inset shows the corresponding Koutecky-Levich plots at different potentials, (c) onset potential, the half-wave potential and diffusion-limiting current of the obtained samples and the commercial 20\% Pt/C and (d) Tafel slopes of SiN-PA900 and the commercial $20 \% \mathrm{Pt} / \mathrm{C}$. 


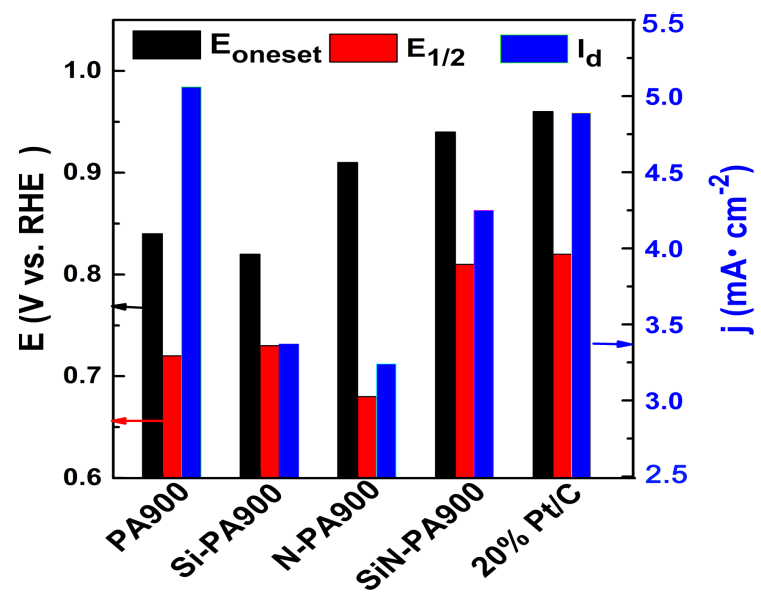

(c)

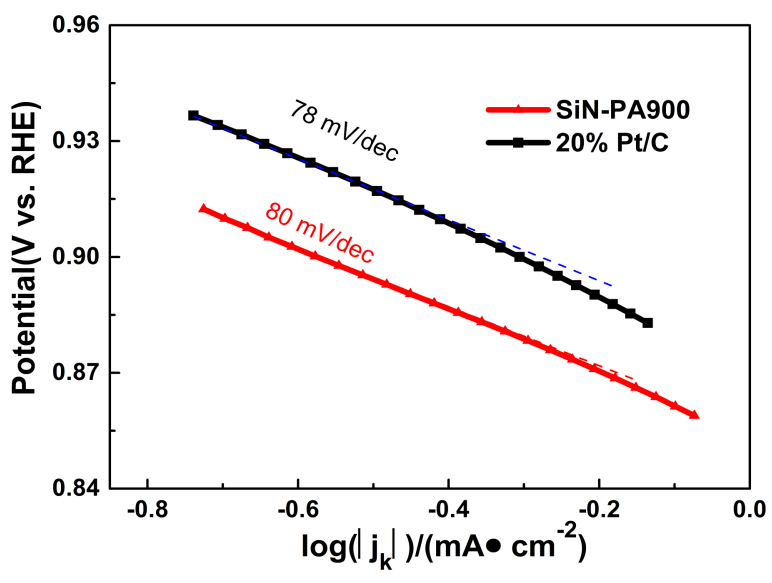

(d)

Fig. 4. (Continued)

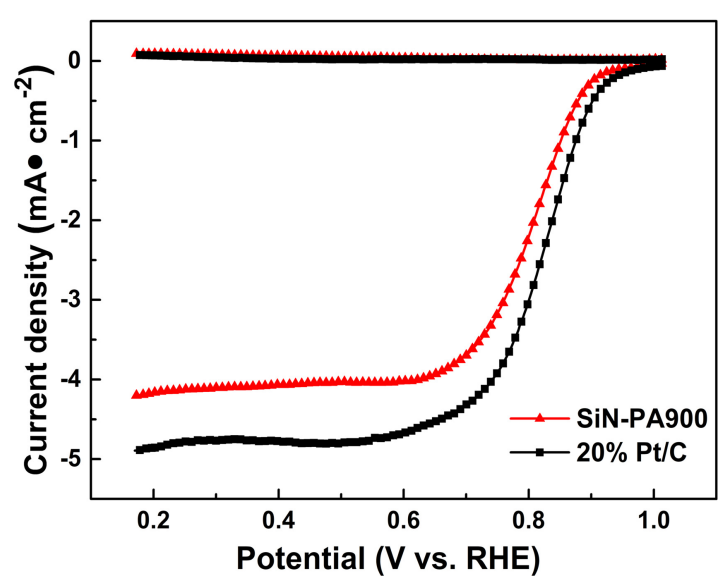

(a)

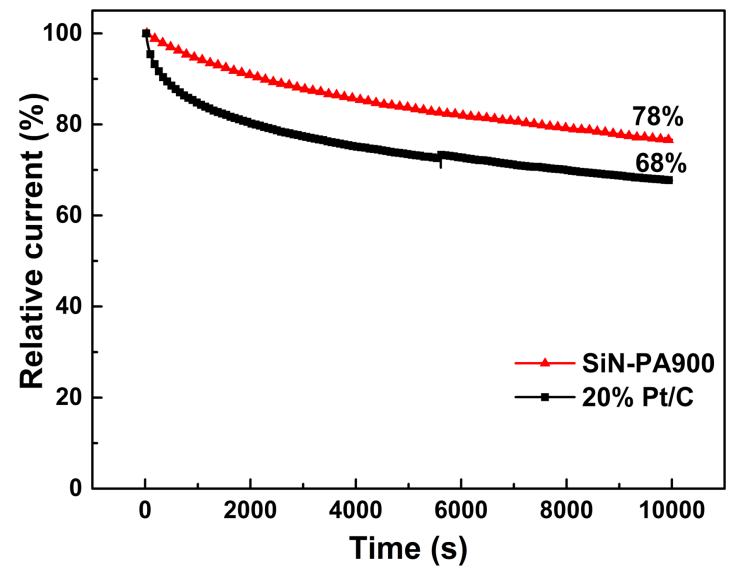

(c)

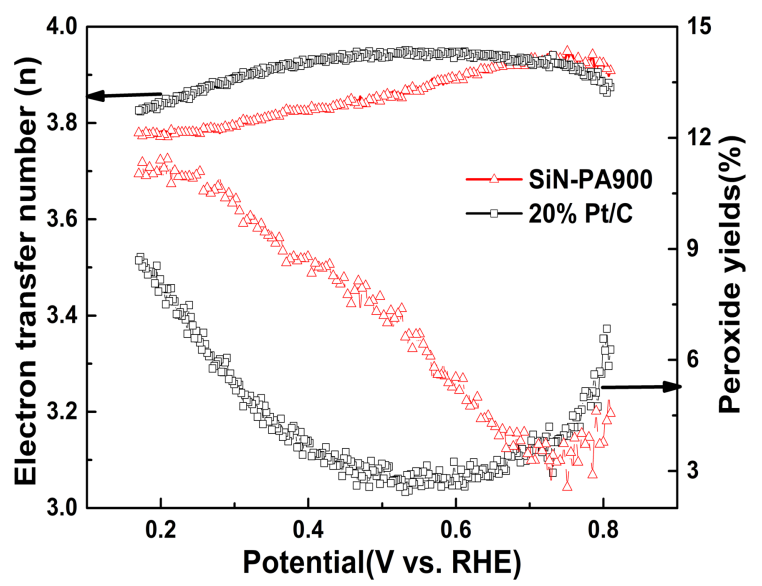

(b)

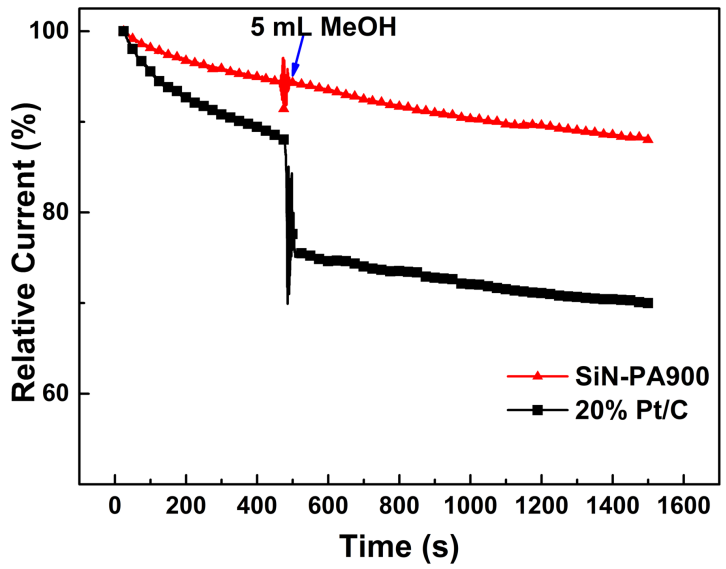

(d)

Fig. 5. (a) RRDE voltammograms of SiN-PA900 and $20 \% \mathrm{Pt} / \mathrm{C}$ electrocatalysts in an $\mathrm{O}_{2}$-saturated $0.10 \mathrm{M}$ aqueous $\mathrm{KOH}$ with a scan rate of $10 \mathrm{mV} / \mathrm{s}$ at $1600 \mathrm{rpm}$, (b) the calculated peroxide percentage at $1.5 \mathrm{~V}$ and the electron transfer number $(n)$ of SiN-PA900 and $20 \% \mathrm{Pt} / \mathrm{C}$ by RRDE at $1600 \mathrm{rpm}$, (c) chronoamperometric response of SiN-PA900 and $20 \% \mathrm{Pt} / \mathrm{C}$ in $\mathrm{O}_{2}$-saturated $0.10 \mathrm{M} \mathrm{KOH}$ electrolyte was conducted at half-wave potential with a rotation speed of $1600 \mathrm{rpm}$ and (d) chronoamperometric response of SiNPA900 and $20 \% \mathrm{Pt} / \mathrm{C}$ at half-wave potential with an addition of $5 \mathrm{~mL}$ methanol. 
SiN-PA900 shows more positive onset potential of 0.94 and half-wave potential of $0.81 \mathrm{~V}$ versus $\mathrm{RHE}$ than those of other samples, which is slightly lower than that of the commercial $20 \% \mathrm{Pt} / \mathrm{C}$ ( $E_{\text {onset }}$ : $\left.0.96 \mathrm{~V}, E_{1 / 2}: 0.82 \mathrm{~V}\right)$. These results strongly demonstrate that the nitrogen, phosphorus and silicon co-doped 3D porous carbon with suitable size and structure can synergistically facilitate the ORR. Note that the ORR performance of SiNPA900 is comparable to that of most of the previously reported ORR catalysts (Table S3). To learn more information about the ORR kinetics of all the samples doped with different heteroatoms, the polarization curves were obtained at various rotation rates, from $400 \mathrm{rpm}$ to $2025 \mathrm{rpm}$ [Figs. 4(b) and S6(a)-S6(c)]. Accordingly, the transferred electron number per oxygen molecule $(n)$ was calculated by $\mathrm{K}-\mathrm{L}$ equation from the polarization curves in the potential range of $0.3-0.5 \mathrm{~V}$ versus RHE. As revealed in the inset of Fig. 4(b), the K-L plots of SiN-PA900 consists of a group of lines with similar slopes, suggesting that they are accorded with first-order reaction kinetics towards the oxygen concentration. ${ }^{43}$ The transferred electron number (n) for SiN-PA900 is calculated to be 3.90 according to the $\mathrm{K}-\mathrm{L}$ equation, indicating a near four-electron dominant transfer pathway for ORR. Furthermore, the Tafel slope [Fig. 4(d)] of SiN-PA900

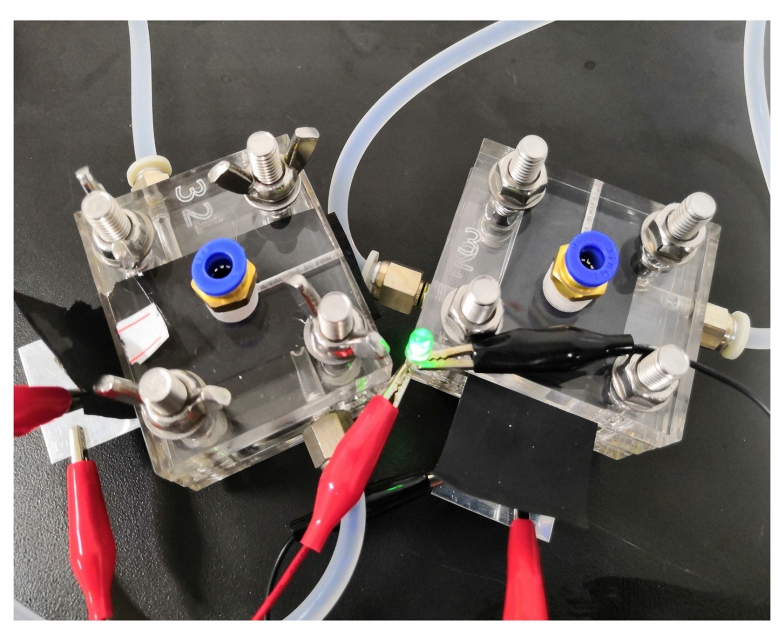

(a)

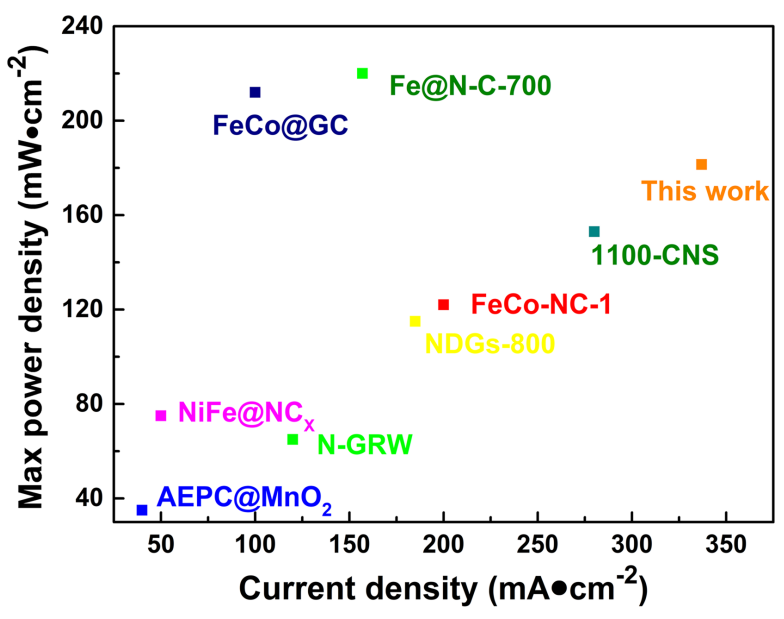

(c)

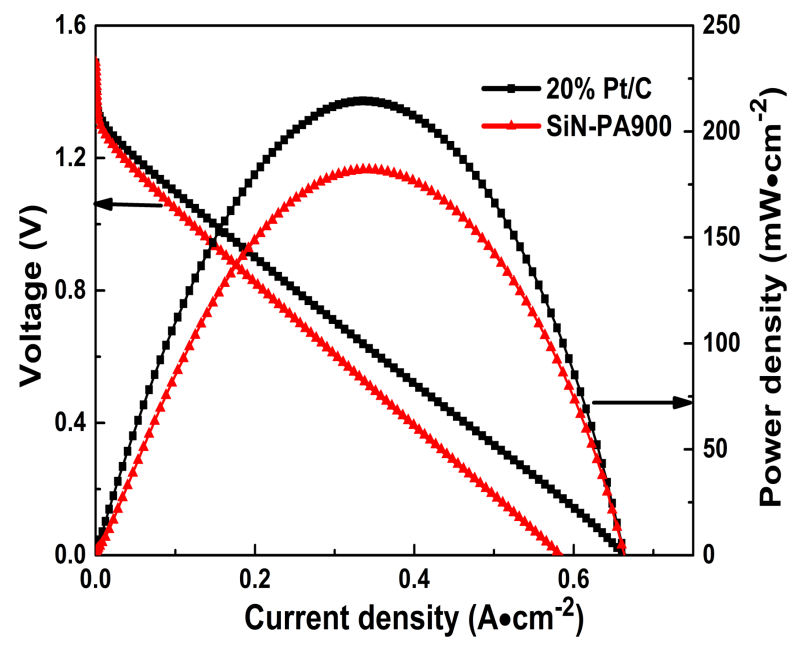

(b)

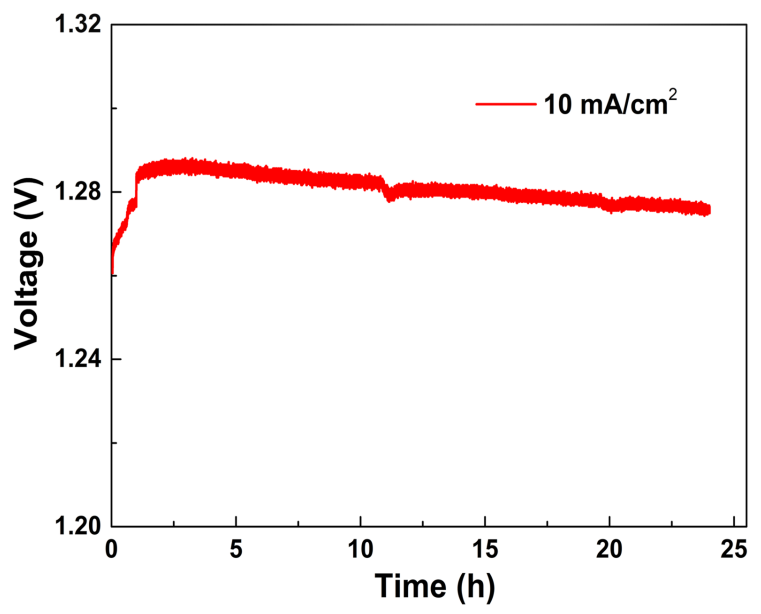

(d)

Fig. 6. (a) Photograph of two tandem primary Zn-air batteries light a green LED (about 3.0 V), (b) discharge polarization curves and power density curves of zine-air batteries using SiN-PA900 and 20\% Pt/C as air cathodes at different current density, (c) a comparison of maximum power density and corresponded discharge current density of SiN-PA900 based Zn-air in this work and of the others in the previous works and (d) galvanostatic discharge curves of Zn-air batteries at current density of $10 \mathrm{~mA} / \mathrm{cm}^{2}$ (color online). 
$\left(80 \mathrm{mV} \mathrm{dec}^{-1}\right)$ is almost equivalent to that of the commercial $20 \% \mathrm{Pt} / \mathrm{C}\left(78 \mathrm{mV} \mathrm{dec}^{-1}\right)$ confirming their similar favorable ORR kinetic process. ${ }^{44}$

Rotating ring-desk electrode (RRDE) measurements were conducted to further evaluate the ORR activity for SiN-PA900 and $20 \% \mathrm{Pt} / \mathrm{C}$ catalysts by calculating the $\mathrm{H}_{2} \mathrm{O}_{2}$ yield $(\%)$ and the electrontransfer number $(n) .{ }^{34}$ As shown in Figs. 5(a) and $5(\mathrm{~b})$, the $\mathrm{H}_{2} \mathrm{O}_{2}$ yield (\%) of SiN-PA900 is slightly higher than that of the commercial $20 \% \mathrm{Pt} / \mathrm{C}$, and its electron transfer number approximating to the $n$ value calculated from the $\mathrm{K}-\mathrm{L}$ plots is slightly lower than that of the commercial $20 \% \mathrm{Pt} / \mathrm{C}$.

For practical applications, durability of the catalysts and its resistance to the methanol crossover effect must be taken into account. Chronoamperometric response measurements were conducted to examine the long-term durability of the SiN-PA900 and the commercial $20 \% \mathrm{Pt} / \mathrm{C}$ catalysts. As shown in Fig. 5(c), 78\% current retention ratio is observed for SiN-PA900 after $10000 \mathrm{~s}$, however, the commercial $\mathrm{Pt} / \mathrm{C}$ shows a lower current retention ratio of $68 \%$ under the same conditions, indicating that the SiN-PA900 is more stable than Pt/C. Figure 5(d) shows the chronoamperometric response of the SiN-PA900 sample recovered quickly after methanol injection, whereas the $20 \% \mathrm{Pt} / \mathrm{C}$ catalyst shows a significant degeneration of current density, demonstrating that SiN-PA900 holds more excellent methanol tolerance than $20 \% \mathrm{Pt} / \mathrm{C}$. Similar results can be seen in Figs. S7(a) and S7(b), the CV curves of $20 \% \mathrm{Pt} / \mathrm{C}$ show that the oxygen reduction peaks disappeared at high methanol oxidation current and the SiN-PA900 demonstrates better resistance to poison. ${ }^{40,45}$

Furthermore, in order to investigate the practical application performance of SiN-PA900 as an air cathode, SiN-PA900 catalyst was first studied using a standard three-electrode electrochemical cell in 6.0 M KOH solution [Fig. S6(d)]. Then primary Znair battery [Fig. 6(a)] was constructed by employing SiN-PA900 as the air cathode. The assembled $\mathrm{Zn}$-air batteries have an open-circuit voltage (OCV) of $1.441 \mathrm{~V}$ and a maximum power density of $181.4 \mathrm{~mW} / \mathrm{cm}^{2}$, which is comparable to that of $20 \%$ $\mathrm{Pt} / \mathrm{C}\left(1.464 \mathrm{~V}, 215 \mathrm{~mW} / \mathrm{cm}^{2}\right)$ as well as most previously reported nonprecious metals ${ }^{46-55}$ [Figs. 6(b) and $6(\mathrm{c})$ ]. To investigate durability of the assembled Zn-air batteries, galvanostatic discharge test was conducted at a current density of $10 \mathrm{~mA} / \mathrm{cm}^{2}$ for a duration for $24 \mathrm{~h}$. As revealed in Fig. 6(d), there is a slight voltage loss, which could be due to the reduction of zinc anode. ${ }^{45}$

\section{Conclusion}

A simple one-step pyrolysis of the mixture of IL consisting of N-methylimidazole and PA and TEOS was developed to construct N, P and Si co-doped 3D porous SiN-PA900 ORR catalyst. The obtained SiN-PA900 exhibited excellent ORR activity, robust durability and superior tolerance for methanol. Its favorable ORR performance may attribute to the synergistic effect caused by N, P and Si in the carbon matrix, good surface wettability, high surface areas and hierarchical porous structures conducive to efficient mass transportation. Remarkably, Zn-air batteries assembled from the SiN-PA900 catalysts exhibited higher power density and excellent discharge stability. This work provides a simple and low-cost way to produce a highly active nonprecious metal catalyst with a great potential application in zinc air battery.

\section{Acknowledgments}

The research was supported by the Opening Project of Material Corrosion and Protection Key Laboratory of Sichuan province (No. 2016CL19), the Key Project of Sichuan Education Department (No. 17ZA0277), the Talent Introduction Funds of Sichuan University of Science and Engineering (No. 2015RC53), the College of Chemical Engineering Sichuan University of Science \& Engineering (No. y2018056) and the Innovation Fund of Postgraduate, Sichuan University of Science \& Engineering (No. y2018055).

\section{References}

1. C. Tang, B. Wang, H. F. Wang and Q. Zhang, Adv. Mater. 29, 1703185 (2017).

2. T. Guo, X. Qin, L. Hou, J. Li, X. Li and Q. Liang, J. Solid State Electrochem. 23, 1359 (2019).

3. T. Liu, L. Zhang, B. Cheng and J. Yu, Adv. Energy Mater. 9, 1803900 (2019).

4. M. Shao, Q. Chang, J. P. Dodelet and R. Chenitz, Chem. Rev. 31, 3594 (2016).

5. J. Fu, R. Liang, G. Liu, A. Yu, Z. Bai, L. Yang and Z. Chen, Adv. Mater. 43, 1805230 (2018).

6. Y. Li and H. Dai, Chem. Soc. Rev. 1, 5257 (2014).

7. L. Yu, Q. Yi, X. Yang and X. Zhou, Nano. 14, 1950028 (2019). 
8. F. Cheng and J. Chen, Chem. Soc. Rev. 41, 2172 (2012).

9. H. Li, Z. Guo and X. Wang, J. Mater. Chem. A 5, 21353 (2017).

10. Z. Deng, Q. Yi, Y. Zhang, H. Nie, G. Li, L. Yu and X. Zhou, Nano. 13, 1850006 (2018).

11. S. Zhang, Y. Shao, G. Yin and Y. Lin, J. Mater. Chem. A 1, 4631 (2013).

12. J. Zhang and C. M. Li, Chem. Soc. Rev. 41, 7016 (2012).

13. Y. Zhao, D. Liu, B, Wang, H. Li, S. Huang, M. Liu, J. Wang, Q. Wang and J. Zhang, Nano Energy 58, 277 (2019).

14. A. Sarapuu, E. Kibena-Põldsepp, M. Borghei and K. Tammeveski, J. Mater. Chem. A 6, 776 (2018).

15. C. H. Choi, S. H Park and S. I Woo, ACS Nano. 6, 7084 (2012).

16. Q. Zhao, Q. Ma, F. Pan, Z. Wang, B. Yang, J. Zhang and J. Zhang, J. Solid State Electrochem. 20, 1469 (2016).

17. X. Qiao, S. Liao, C. You and R. Chen, Catalysts. 5, $981(2015)$.

18. S. K. Ramasahayam and T. Viswanathan, Int. J. Electrochem. Sci. 11, 200 (2016).

19. J. Liang, Y. Zheng, J. Chen, J. Liu, D. Hulicovajurcakova, M. Jaroniec and S. Qiao, Angew. Chem. 51, 3892 (2012).

20. S. C. Abbas, K. Ding, Q. Liu, Y. Huang, Y. Bu, J. Wu, J. Lv, M. A. Ghausi and Y. Wang, J. Mater. Chem. A 4, 7924 (2016).

21. P. Zhang, X. Hou, J. Mi, Y. He, L. Lin, Q. Jiang and M. Dong, Phys. Chem. Chem. Phys. 16, 17479 (2014).

22. J. Duan, S. Chen, S. Dai and S. Z. Qiao, Adv. Funct. Mater. 24, 2072 (2014).

23. S. K. Ramasahayam, Z. Hicks and T. Viswanathan, ACS Sustain Chem. Eng. 3, 2194 (2015).

24. J. S. Lee, X. Wang, H. Luo and S. Dai, Adv. Mater. 22, 1004 (2010).

25. J. P. Paraknowitsch, J. Zhang, D. Su, A. Thomas and M. Antonietti, Adv. Mater. 22, 87 (2010).

26. Z. Cui, S. Wang, Y. Zhang and M. Cao, J. Power Sources 259, 138 (2014).

27. J. P. Paraknowitsch and A. Thomas, Macromol. Chem. Phys. 213, 1132 (2012).

28. N. Fechler, T. P. Fellinger and M. Antonietti, Adv. Mater. 25, 75 (2013).

29. J. Zhang, Z. Zhao, Z. Xia and L. Dai, Nat. Nanotechnol. 10, 444 (2015).

30. T. Wu, G. Wang, X. Zhang, C. Chen, Y. Zhang and H. Zhao, Chem. Commun. 51, 1334 (2015).

31. Y. Su, Y. Zhu, H. Jiang, J. Shen, X. Yang, W. Zou, J. Chen and C. Li, Nanoscale. 6, 15080 (2014).

32. X. Mao, Z. Cao, Y. Yin, Z. Wang, H. Dong and S. Yang, Int. J. Hydrogen Energy 43, 10341 (2018).
33. C. Hu, X. Zhai, L. Liu, Y. Zhao, L. Jiang and L. Qu, Sci. Rep. 3, 2065 (2013).

34. Y. Zan, Z. Zhang, H. Liu, M. Dou and F. Wang, J. Mater. Chem. A 5, 24329 (2017).

35. X. Liu, W. Zhou, L. Yang, L. Li, Z. Zhang, Y. Ke and S. Chen, J. Mater. Chem. A 3, 8840 (2015).

36. B. O. K. N. Kudin, H. C. Schniepp, R. K. Prudhomme, I. A. Aksay and R. Car, Nano Lett. 8, 36 (2008).

37. M. A. Nahi and P. T. Williams, Biomass Bioenergy 37, 142 (2012).

38. J. Duan, S. Chen and C. Zhao, Nat. Commun. 8, 15341 (2017).

39. G. Ferrero, K. Preuss, A. Fuertes, M. Sevilla and M. Titirici, J. Mater. Chem. A 4, 2581 (2016).

40. M. Zhang, M. M. Zhang, Y. S. Wei, X. Y. Dong and S. Q. Zang, ChemistrySelec 2, 6129 (2017).

41. I. Alonso-Lemus, M. Figueroa-Torres, A. GarcíaHernández, B. Escobar-Morales, F. RodríguezVarela, A. Fuentes, D. Lardizabal-Gutierrez and P. Quintana-Owen, Int. J. Hydrogen Energy 42, 30330 (2017).

42. Z. Liu, X. Fu, M. Li, F. Wang, Q. Wang, G. Kang and F. Peng, J. Mater. Chem. A 3, 3289 (2015).

43. B. Y. Xia, Y. Yan, N. Li, H. B. Wu, X. W. D. Lou and X. Wang, Nat. Energy 1, 15006 (2016).

44. W. Niu, L. Li, X. Liu, N. Wang, J. Liu, W. Zhou, Z. Tang and S. Chen, J. Am. Chem. Soc. 1, 5555 (2015).

45. G. Liu, Z. Liu, J. Li, M. Zeng, Z. Li, L. He and F. Li, Carbon 137, 68 (2018).

46. Q. Wang, Y. Ji, Y. Lei, Y. Wang, Y. Wang, Y. Li and S. Wang, ACS Energy Lett. 3, 1183 (2018).

47. H. B. Yang, J. Miao, S. F. Hung, J. Chen, H. B. Tao, X. Wang, L. Zhang, R. Chen, J. Gao and H. M. Chen, Sci Adv. 2, e1501122 (2016).

48. C. Hu and L. Dai, Adv. Mater. 29, 1604942 (2017).

49. B. Li, J. Chai, X. Ge, T. An, P. C. Lim, Z. Liu and Y. Zong, ChemNanoMat. 3, 401 (2017).

50. B. Zhong, L. Zhang, J. Yu and K. Fan, J. Colloid Interface Sci. 546, 113 (2019).

51. G. Nam, J. Park, M. Choi, P. Oh, S. Park, M. G. Kim, N. Park, J. Cho and J. S. Lee, ACS Nano 9, 6493 (2015).

52. J. Wang, H. Wu, D. Gao, S. Miao, G. Wang and X. Bao, Nano Energy 13, 387 (2015).

53. Z. Pei, H. Li, Y. Huang, Q. Xue, Y. Huang, M. Zhu, Z. Wang and C. Zhi, Energy Environ. Sci. 10, 742 (2017).

54. C. Y. Su, H. Cheng, W. Li, Z. Q. Liu, N. Li, Z. Hou, F. Q. Bai, H. X. Zhang and T. Y. Ma, Adv Energy Mater. 7, 1602420 (2017).

55. J. Zhu, M. Xiao, Y. Zhang, Z. Jin, Z. Peng, C. Liu, S. Chen, J. Ge and W. Xing, ACS Catal. 6, 6335 (2016). 


\section{Supporting Information}

Table S1. Summary of pore structure characterization for PA900, Si-PA900, N-PA900 and SiN-PA900.

\begin{tabular}{lcccc}
\hline Samples & $S_{\text {BET }}\left(\mathrm{m}^{2} / \mathrm{g}\right)$ & $V_{\text {total }}\left(\mathrm{cm}^{3} / \mathrm{g}\right)$ & $V_{\text {micro }}$ & $V_{\text {micro }}(\%)$ \\
\hline PA900 & 1233.8 & 1.3604 & 0.5657 & 41.6 \\
Si-PA900 & 343.8 & 0.4405 & 0.1518 & 34.5 \\
N-PA900 & 517.8 & 0.3774 & 0.2552 & 67.6 \\
SiN-PA900 & 684.7 & 0.4648 & 0.3309 & 71.2 \\
\hline
\end{tabular}

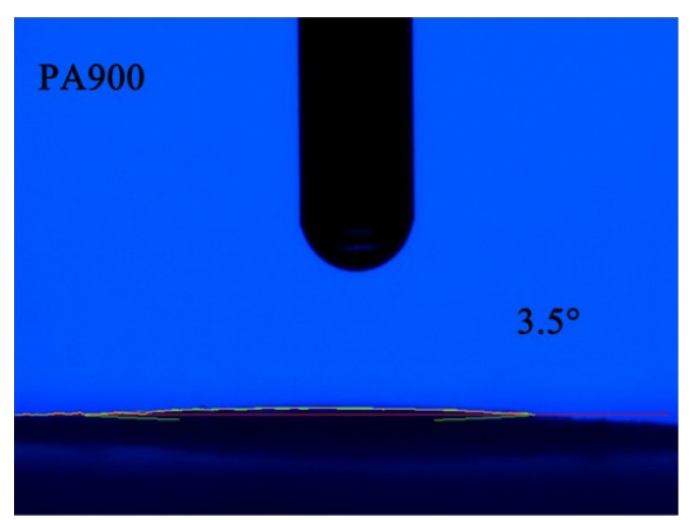

(a)

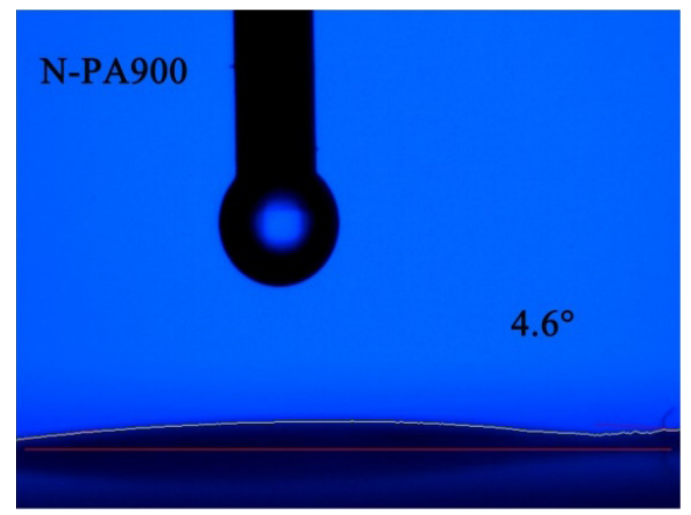

(c)

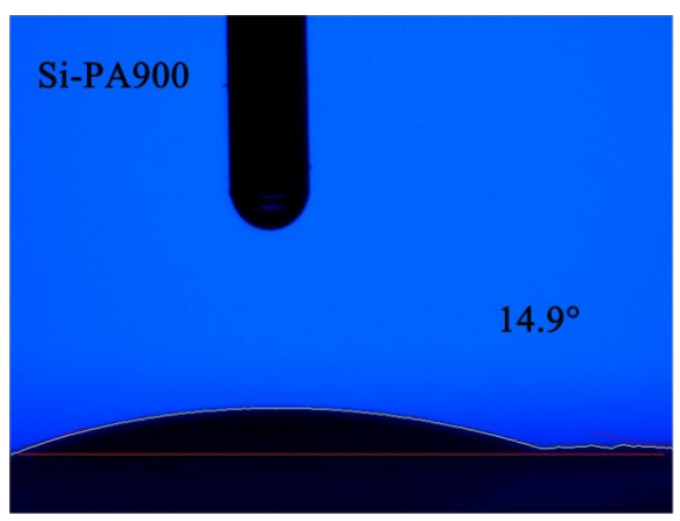

(b)

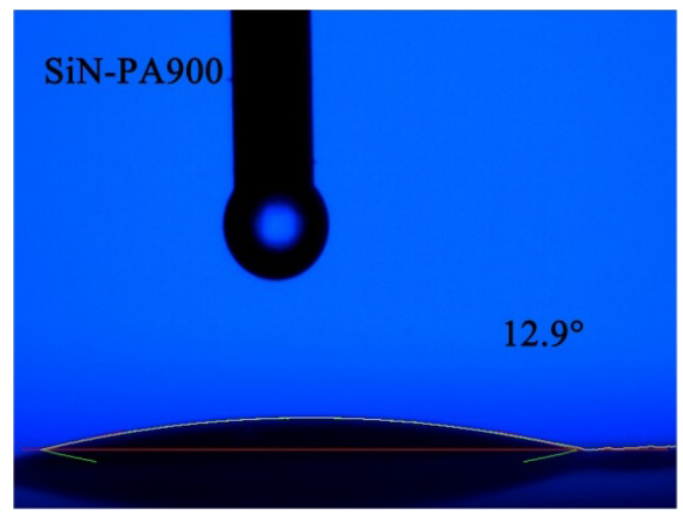

(d)

Fig. S1. Contact angle measurements of PA900, Si-PA900, N-PA900 and SiN-PA900.

Table S2. The element content of PA900, Si-PA900, N-PA900 and SiN-PA900 were determined by XPS.

\begin{tabular}{lccccc}
\hline & \multicolumn{5}{c}{ Atomic composition (at.\%) } \\
\cline { 2 - 6 } Samples & $\mathrm{C}$ & $\mathrm{O}$ & $\mathrm{N}$ & $\mathrm{P}$ & $\mathrm{Si}$ \\
\hline PA900 & 81.16 & 15.08 & 0 & 3.76 & 0 \\
Si-PA900 & 71.61 & 21.37 & 0 & 1.74 & 5.28 \\
N-PA900 & 74.14 & 17.84 & 4.23 & 3.79 & 0 \\
SiN-PA900 & 74.37 & 14.55 & 4.08 & 3.41 & 3.59 \\
\hline
\end{tabular}




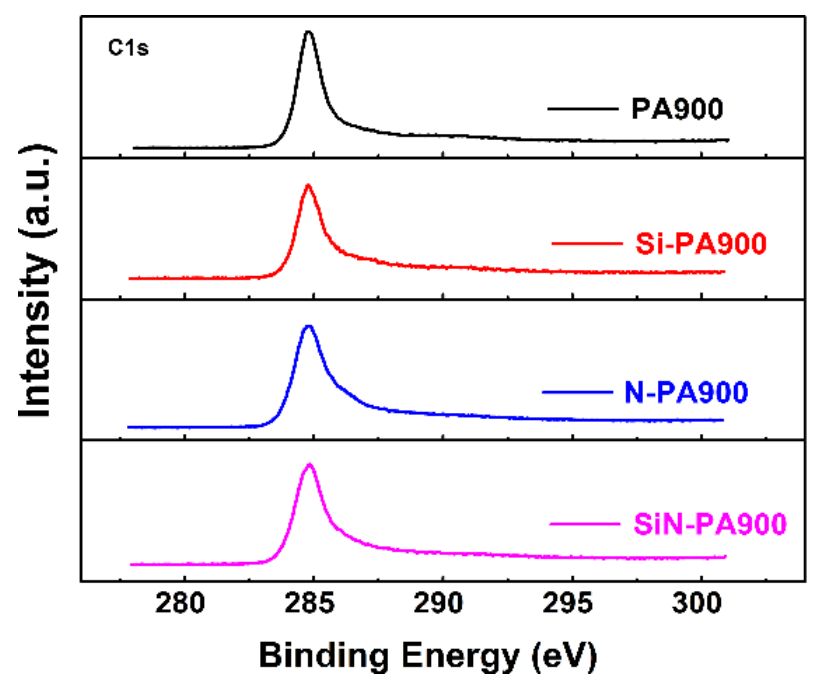

(a)

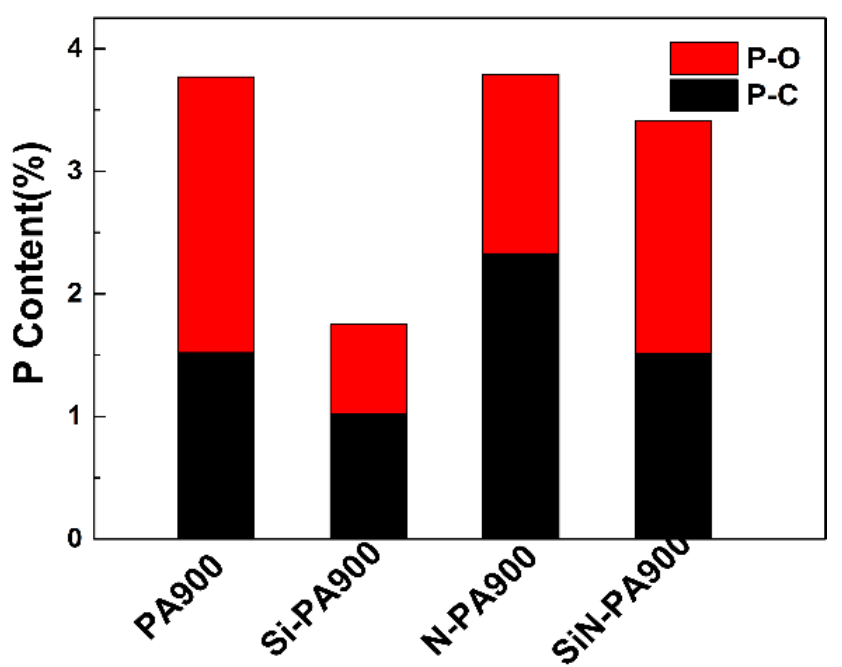

(b)

Fig. S2. The high-resolution XPS spectra of (a) C1s for the obtained samples and (b) the content of the P-C and P-O in the four samples.

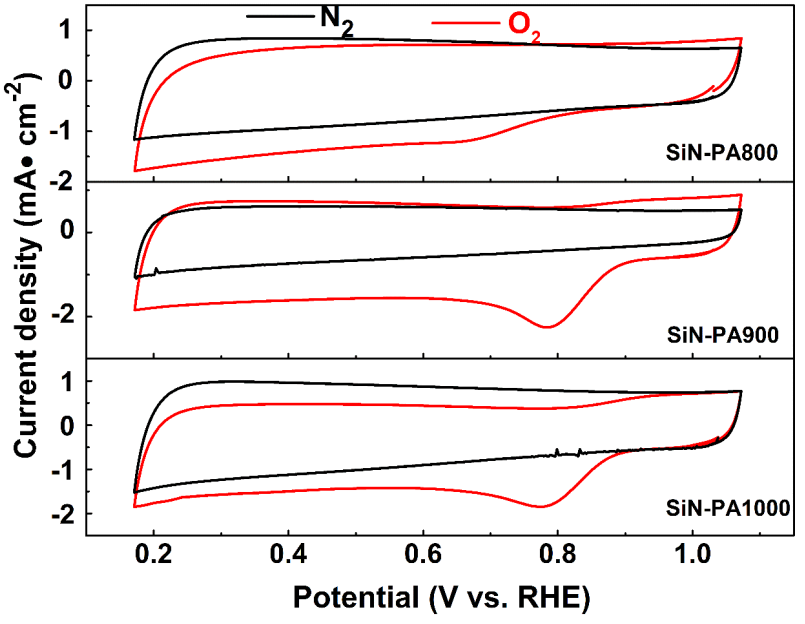

Fig. S3. CV curves of SiN-PA800, SiN-PA900 and SiNPA1000 in $\mathrm{N}_{2}$-saturated (the black line) and $\mathrm{O}_{2}$-saturated (the red line) $0.10 \mathrm{M} \mathrm{KOH}$ (color online).

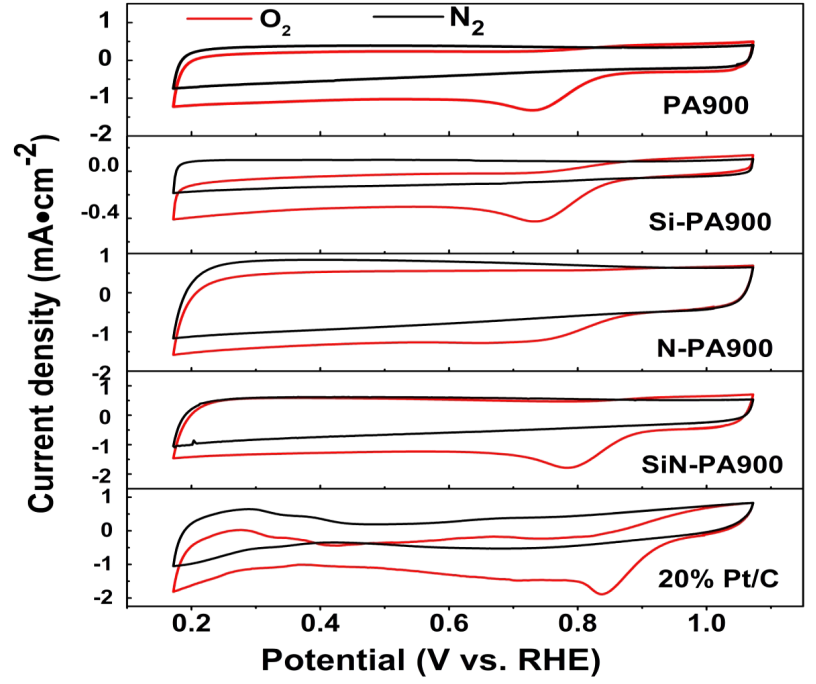

Fig. S4. CV curves of PA900, Si-PA900, N-PA900 and SiN-PA900, 20\% Pt/C in $\mathrm{N}_{2}$-saturated (the black line) and $\mathrm{O}_{2}$-saturated (the red line) $0.10 \mathrm{M} \mathrm{KOH}$ with a scan rate of $50 \mathrm{mV} / \mathrm{s}$ (color online). 


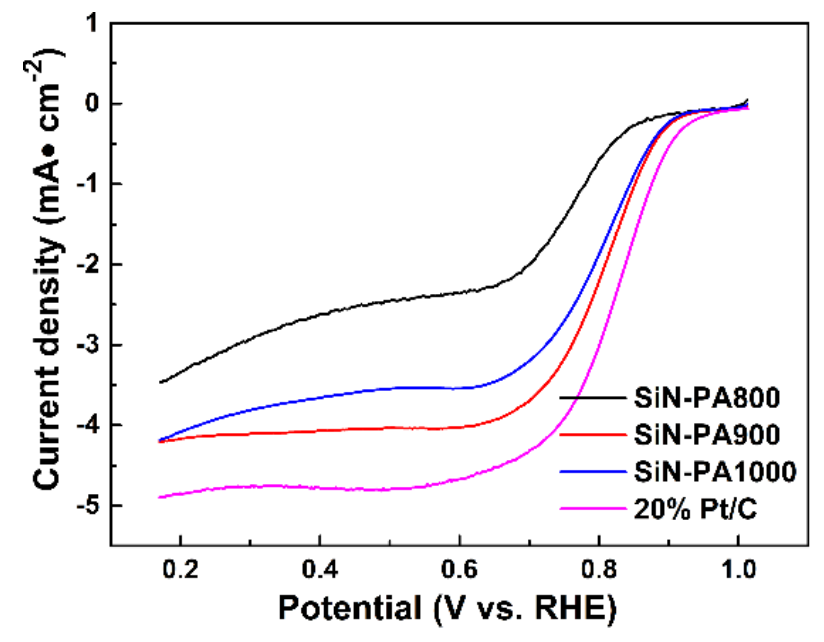

(a)

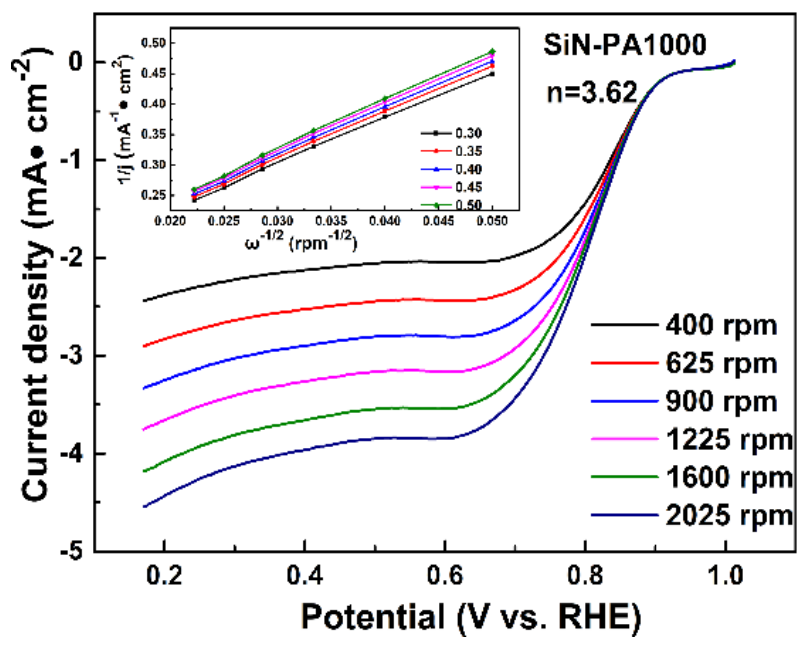

(c)

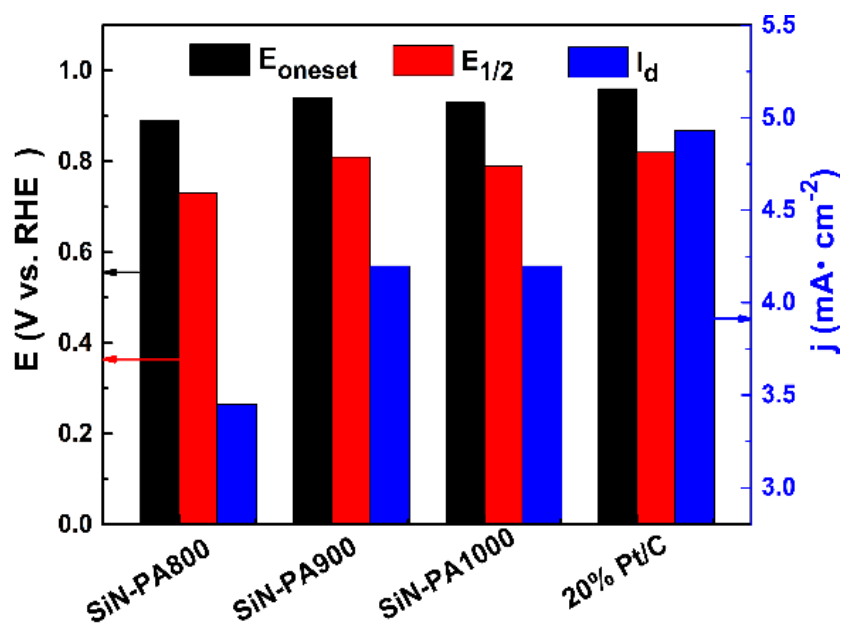

(b)

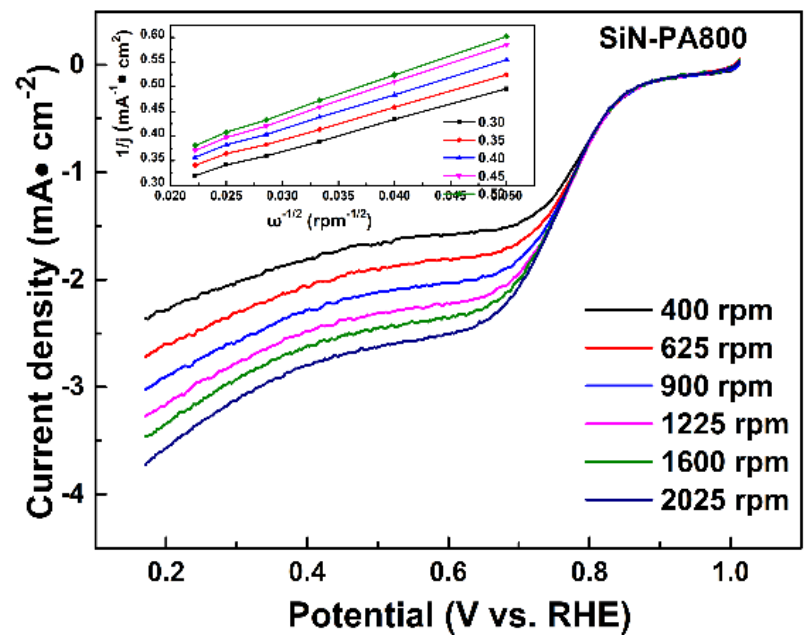

(d)

Fig. S5. (a) Comparison of the LSV curves for SiN-PA800, SiN-PA900, SiN-PA1000 and 20\% Pt/C catalyst, (b) onset potential, the half-wave potential and diffusion-limiting current of the obtained samples with different pyrolysis temperature and $20 \% \mathrm{Pt} / \mathrm{C}$, LSV curves of (c) SiN-PA1000 and (d) SiN-PA800 recorded from different rotating speeds in $0.1 \mathrm{M}$ KOH and inset shows the corresponding Koutecky-Levich plots at different potentials. 


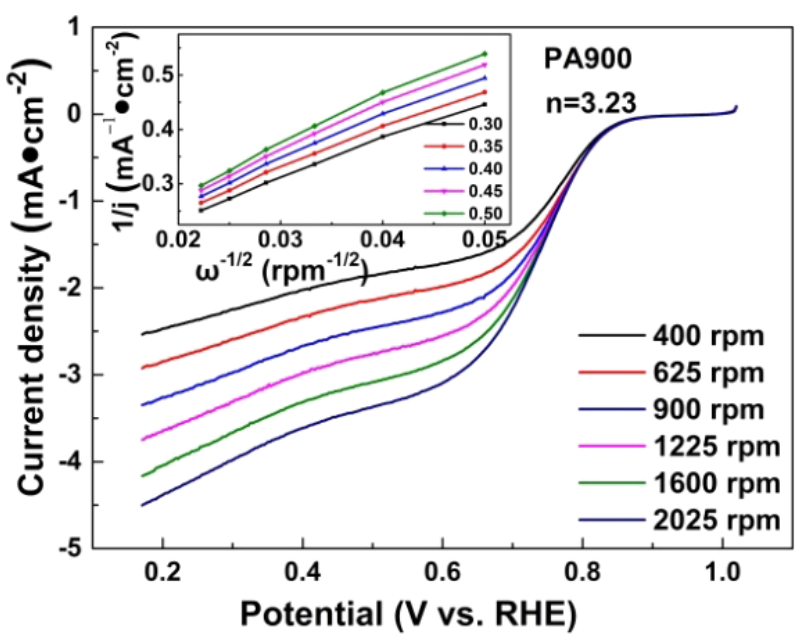

(a)

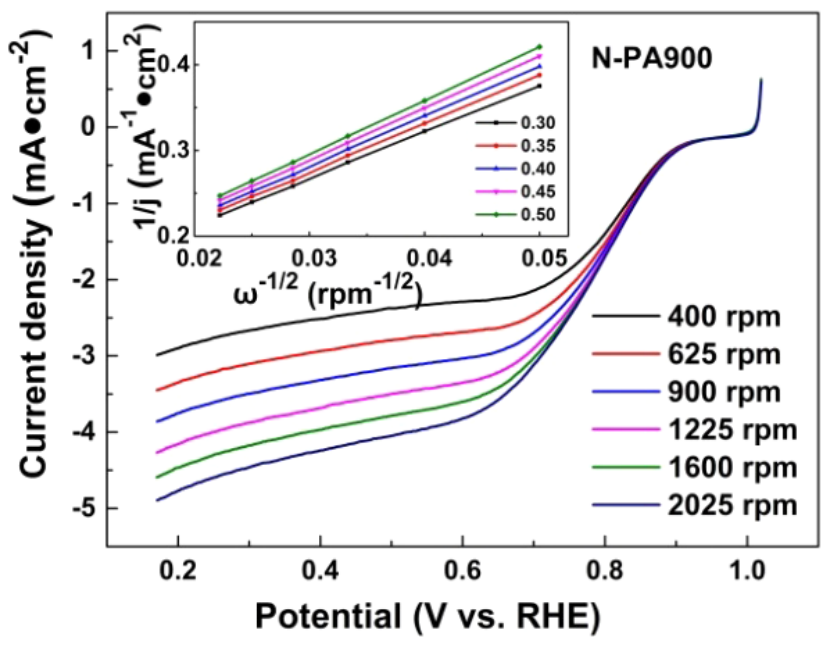

(c)

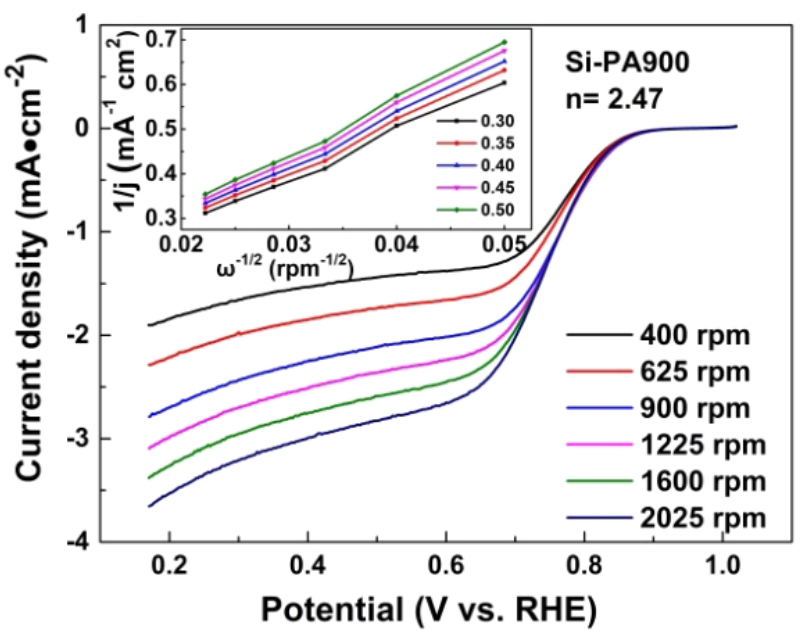

(b)

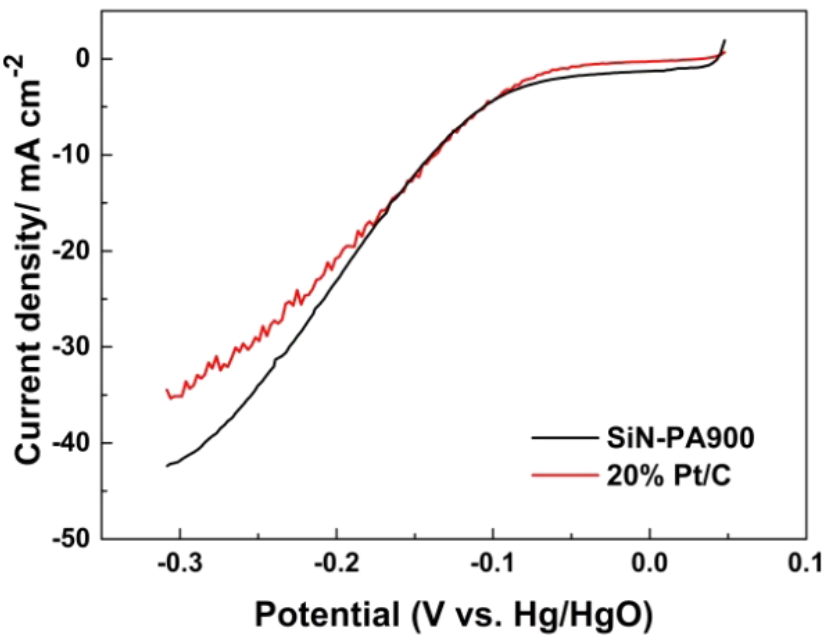

(d)

Fig. S6. LSV curves of (a) PA900, (b) Si-PA900 and (c) N-PA900 in $\mathrm{O}_{2}$-saturated $0.10 \mathrm{M} \mathrm{KOH}$ with a scan rate of $10 \mathrm{mV} / \mathrm{s}$ at different rotating speeds and inset shows the corresponding Koutecky-Levich plots at different potentials and (d) LSV curses of SiNPA900 and 20\% Pt/C in $\mathrm{O}_{2}$-saturated $6.0 \mathrm{M} \mathrm{KOH}$ with scan rate of $10 \mathrm{mV} / \mathrm{s}$. The mass density of the catalyst on the carbon sheet is $1 \mathrm{mg} / \mathrm{cm}^{2}$.

Table S3. Comparison of electrocatalytic ORR performance for previously reported ORR catalysts in $0.10 \mathrm{M} \mathrm{KOH}$ solution.

\begin{tabular}{|c|c|c|c|c|c|}
\hline Catalysts & Loading mass $\left(\mu \mathrm{g} / \mathrm{cm}^{2}\right)$ & $E_{\text {Onset }}(V$ versus $\mathrm{RHE})$ & $E_{1 / 2}(V$ versus $\mathrm{RHE})$ & $I_{d}\left(\mathrm{~mA} / \mathrm{cm}^{2}\right)$ & Reference \\
\hline SiN-PA900 & 142.16 & 0.94 & 0.81 & 4.2 & This work \\
\hline NPC-1000 & 318 & 0.93 & 0.79 & 4.83 & 1 \\
\hline $\mathrm{NPC} / \mathrm{G}$ & 250 & 0.95 & 0.81 & 5.8 & 2 \\
\hline $\mathrm{Co} / \mathrm{CoO}_{x}-\mathrm{N}-\mathrm{C}-\mathrm{l}$ & 181 & 0.90 & 0.83 & 4.90 & 3 \\
\hline NP-PCN & 212 & 0.91 & 0.82 & 4.60 & 4 \\
\hline AC-F-U-P & 306 & 0.83 & 0.772 & 5.2 & 5 \\
\hline $\mathrm{S}-\mathrm{N} / \mathrm{C}$ & 140 & 0.99 & 0.85 & 5.8 & 6 \\
\hline $\mathrm{N}, \mathrm{S}-\mathrm{CN}$ & 200 & 0.92 & 0.77 & 4.3 & 7 \\
\hline NPCN-900 & 204 & 0.94 & 0.78 & 5.5 & 8 \\
\hline Fe-TCNQ-900 & 200 & 0.94 & 0.82 & 7.5 & 9 \\
\hline
\end{tabular}


R. Huang et al.

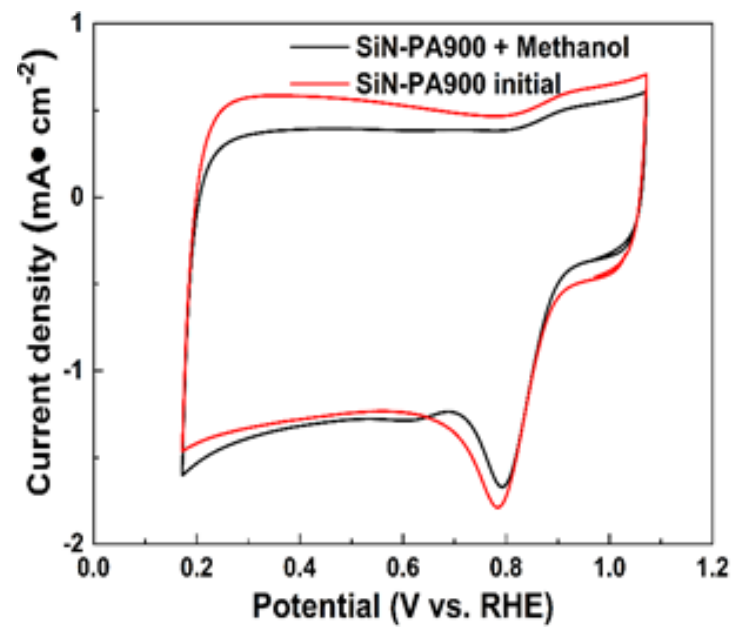

(a)

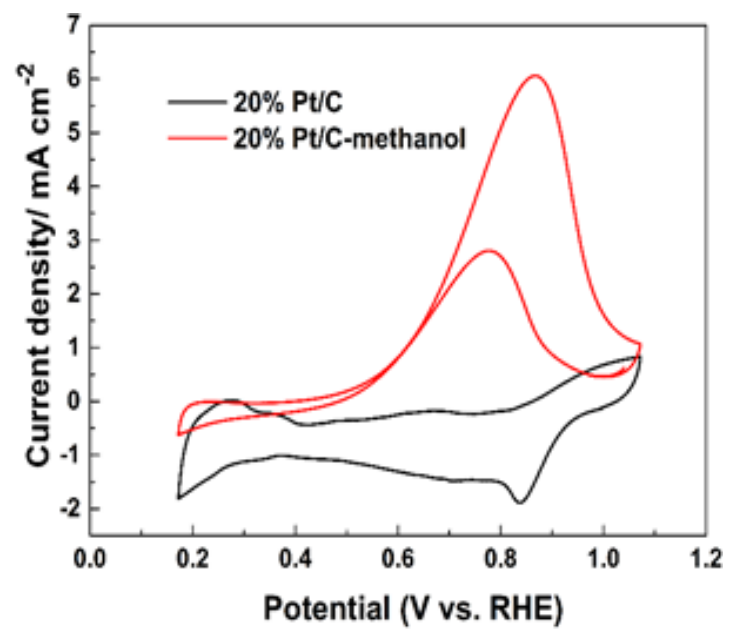

(b)

Fig. S7. CV curves of (a) SiN-PA900 and (b) $20 \% \mathrm{Pt} / \mathrm{C}$ in $\mathrm{O}_{2}$-saturated $0.10 \mathrm{M} \mathrm{KOH}$ electrolyte with and without methanol at a scan rate of $50 \mathrm{mV} / \mathrm{s}$.

\section{References}

1. X. Mao, Z. Cao, Y. Yin, Z. Wang, H. Dong and S. Yang, Int. J. Hydrogen Energy 43, 10341 (2018).

2. G. Liu, Z. Liu, J. Li, M. Zeng, Z. Li, L. He and F. Li, Carbon 137, 68 (2018).

3. J. Guo, B. Chen, Q. Hao, J. Nie and G. Ma, Appl. Surf. Sci. 456, 959 (2018).

4. F. Pan, Y. Duan, A. Liang, J. Zhang and Y. Li, Electrochim. Acta 238, 375 (2017).

5. N. L. Maryam Borghei, E. Kibenapoldsepp, L. S. Johansson, J. M. Campbell, E. I. Kauppinen,
K. Tammeveski, O. J. Rojas, Appl. Catal. B-Environ. 204, 394 (2014).

6. J. Yang, X. Zhou, D. Wu, X. Zhao and Z. Zhou, Adv. Mater. 29, 1604108 (2017).

7. K. Qu, Y. Zheng, S. Dai and S. Z. Qiao, Nano Energy 19, 373 (2016).

8. H. Jiang, Y. Wang, J. Hao, Y. Liu, W. Li and J. Li, Carbon 122, 64 (2017).

9. L. Wei, H. Sun, T. Yang, S. Deng, M. Wu and Z. Li, Appl. Surf. Sci. 439, 439 (2018). 